\title{
NBSIR 81-2304
}

\section{Economic Framework for Cost-Effective Residential Water Conservation Decisions}

U.S. DEPARTMENT OF COMMERCE

National Bureau of Standards

National Engineering Laboratory

Center for Building Technology

Building Economics and Regulatory Technology Division

Washington, DC 20234

August 1981

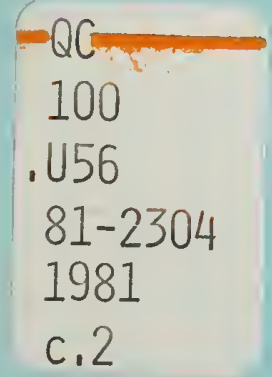

Prepared for:

Department of Housing and Urban Development

Office of Policy Development and Research 



\section{ECONOMIC FRAMEWORK FOR}

COST-EFFECTIVE RESIDENTIAL WATER CONSERVATION DECISIONS

Stephen F. Weber

Bruce E. Thompson

Barbara C. Lippiatt

U.S. DEPARTMENT OF COMMERCE

National Bureau of Standards

National Engineering Laboratory

Center for Building Technology

Building Economics and Regulatory Technology Division

Washington, DC 20234

August 1981

Prepared for:

Department of Housing and Urban Development Office of Policy Development and Research

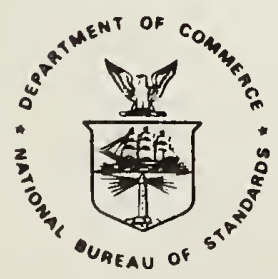

U.S. DEPARTMENT OF COMMERCE, Malcolm Baldrige, Secretary NATIONAL BUREAU OF STANDARDS, Ernest Ambler, Director 



\section{PREFACE}

TગA T2EA

This report is one of a group documenting National Bureau of Standards (NBS) fager

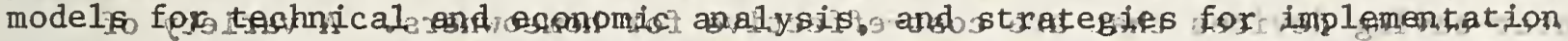

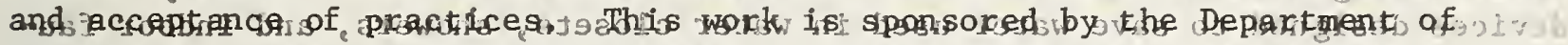

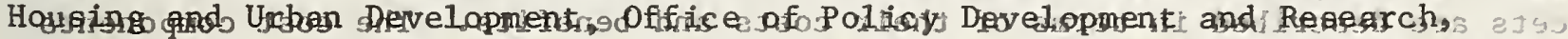

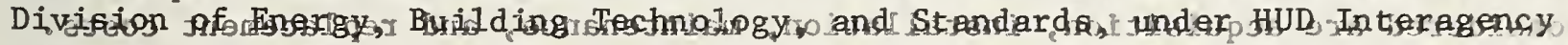

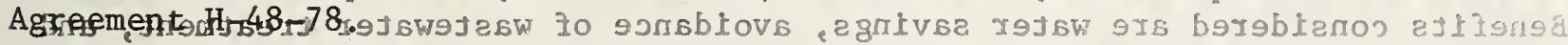

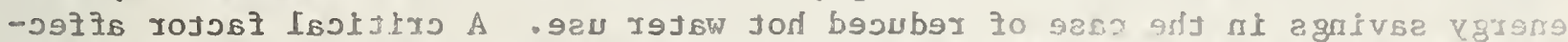

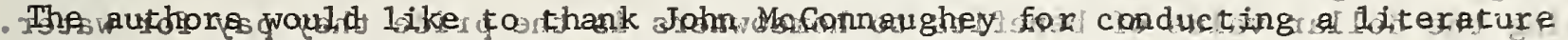

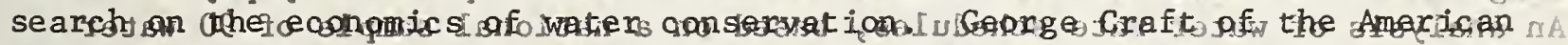

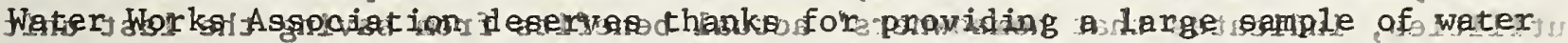

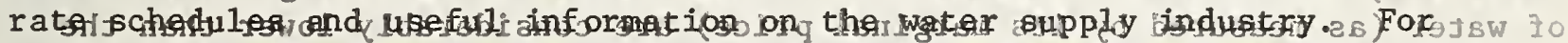

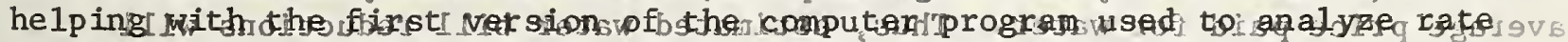

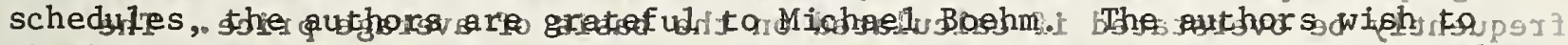

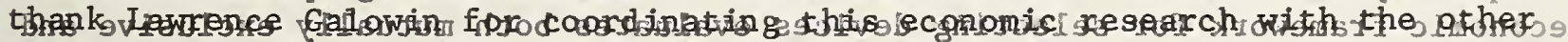

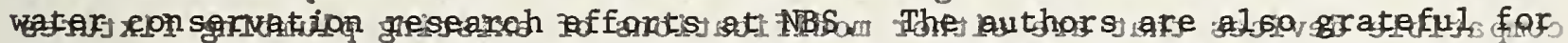

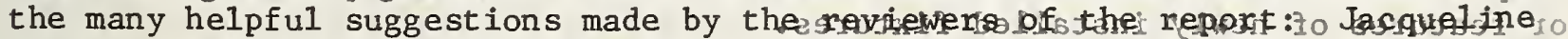
Elder, Anne Hillstrom, Harold Marsha11, Robert Palla, Fred Rudder, and Reeves

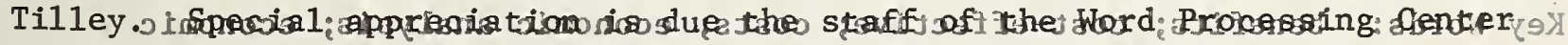

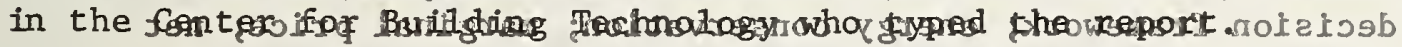




\section{ABSTRACT}

This report presents an economic framework for utilities to use in recommending water-saving devices that are cost-effective for homeowners. A variety of devices designed to save water used in water closets, showers, and indoor faucets are described in terms of their costs and benefits. The cost components considered are acquisition, installation, maintenance, and replacement costs. Benefits considered are water savings, avoldance of wastewater treatment, and energy savings in the case of reduced hot water use. A critical factor affecting the dollar value of benefits to homeowners is the price they pay for water. An analysis of water rate schedules, based on a national sample of 90 water utilities, indicates that homeowners' actual benefits from saving the last unit of water (as measured by its marginal price) are considerably lower than the average price pald for water. Thus, estimated water bill reductions will frequently be overstated if calculated on the basis of average price. The economic framework for selecting devices evaluates both mutually exclusive and compatible devices that are either modifications of existing plumbing fixtures' or features of newly installed fixtures.

Key Words: benefits; cost-effective; costs; economic analysis; economic decision framework; energy conservation; marginal price; net present value; residential water conservation; wastewater treatment; water rate schedules; water-saving devices. 


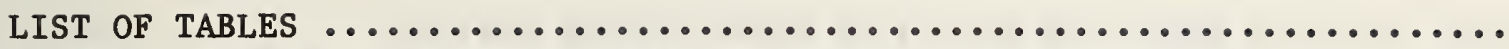
CONVERSION FACTORS FROM CUSTOMARY TO METRIC (SI) UNITS ............

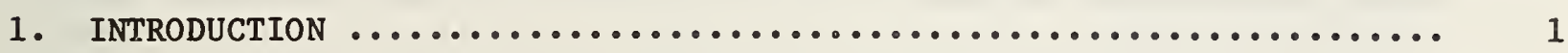

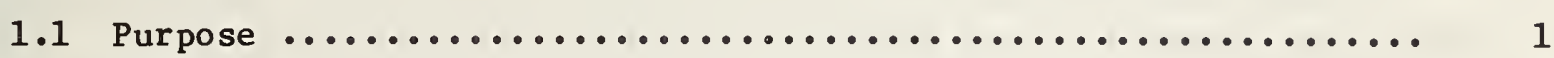

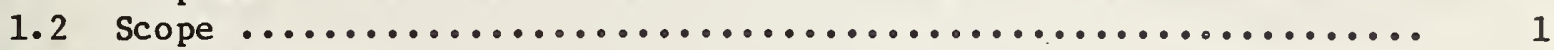

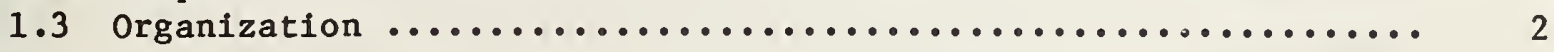

2. DESCRIPTION OF WATER CONSERVATION DEVICES $\ldots \ldots \ldots \ldots \ldots \ldots \ldots \ldots . \ldots . \ldots$

2.1 Water Closet Devices ................................ 3

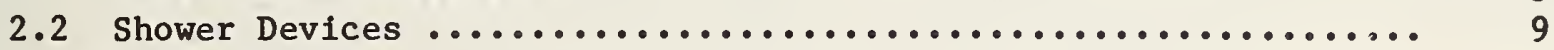

2.3 Faucet Devices ...................................... 10

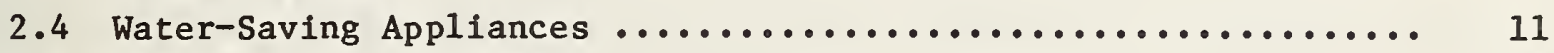

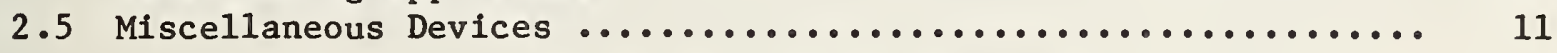

3. COST AND BENEFIT COMPONENTS OF WATER-SAVING DEVICES $\ldots \ldots \ldots \ldots \ldots \ldots$

3.1 Cost Components .................................. 13

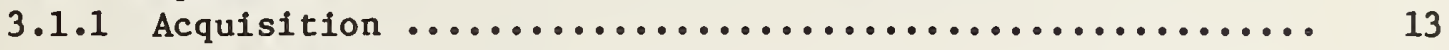

3.1 .2 Installation .............................. 17

3.1 .3 Operation, Maintenance, and Repair ................ 19

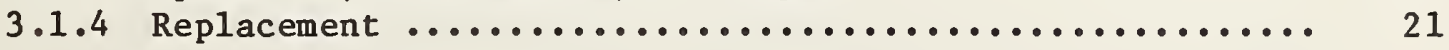

3.2 Benefit Components ................................. 23

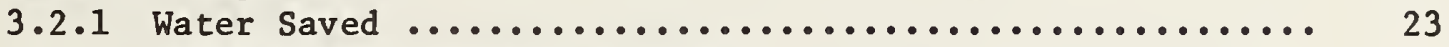

3.2 .2 Wastewater Treatment Avoided $. . \ldots \ldots \ldots \ldots \ldots \ldots \ldots \ldots \ldots, 25$

3.2 .3 Energy Saved $\ldots \ldots \ldots \ldots \ldots \ldots \ldots \ldots \ldots \ldots \ldots \ldots \ldots, 30$

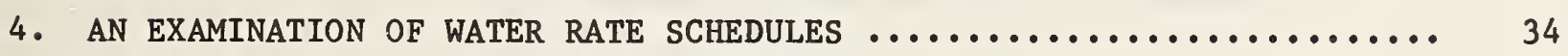

4.1 Types of Rate Schedules ............................. 34

4.1.1 Fixed Charge Per Period Schedule .................. 34

4.1 .2 Uniform Rate Per Unit Schedule .................... 34

4.1 .3 Varying Rates Per Unit Schedules .................. 35

4.1.4 Peak Load Pricing Schedules ...................... 35

4.1 .5 Mixed Schedules .............................. 35

4.1.6 Conservation Potential of Rate Schedule Types ........ 37

4.2 Analysis of a National Sample of Rate Schedules ........... 37

4.2.1 Sample Selection ............................. 37

4.2.2 Mean Values of Rate Schedule Variables .............. 40

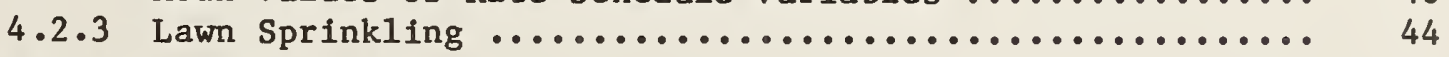

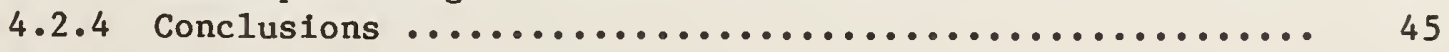


TABLE OF CONTENTS (Continued)

$\underline{\text { Page }}$

5. ECONOMIC DECISION RULES FOR SELECTING WATER-SAVING DEVICES ....... 46

5.1 Mutually Exclusive Devices .......................... 46

5.2 Compatible Devices ............................... 49

6. SUMMARY AND SUGGESTIONS FOR RESEARCH ...................... 52

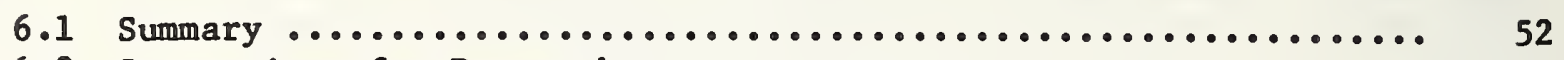

6.2 Suggestions for Research $\ldots \ldots \ldots \ldots \ldots \ldots \ldots \ldots \ldots \ldots \ldots \ldots \ldots \ldots \ldots . \ldots \ldots$

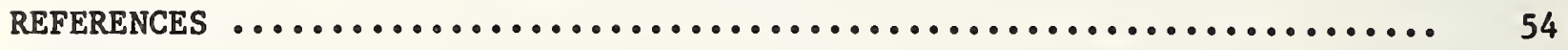


Table 2.1 Water-Saving Devices .............................. 4

Table 2.2 Percentage Distribution of Domestic Water Use by Function .... 5

Table 3.1 Acquisition Costs of Selected Water-Saving Devices Used in

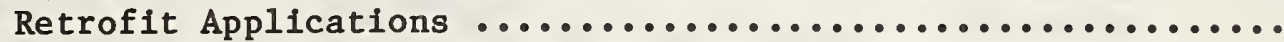

Table 3.2 Selected Water-Saving Devices that Homeowners could Install, Operate, and Maintain at No Financial Cost ............. 18

Table 3.3 Installation Costs $(\$)$ of Selected Water-Saving Devices Used In New and Retrofit Applications .................... 20

Table 3.4 Expected Lifetimes of Selected Water-Saving Devices .........

Table 3.5 Estimated Water Savings of Various Devices ................

Table 3.6 Annual O\&M Costs for Non-Lagoon Secondary Treatment

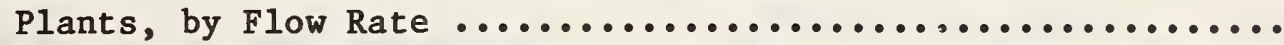

Table 3.7 Cost of New Non-Lagoon Secondary Treatment Plant Construction,

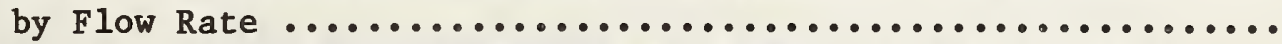

Table 3.8 Frequencies of Occurrence, Assumed Efficiencies, and Fuel Prices for Residential Water Heating Systems, by Type of

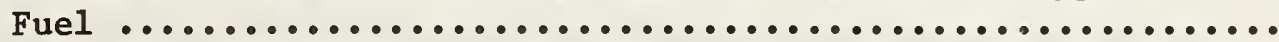

Table 3.9 Daily Water Savings, Water Service Temperatures, and Annual Dollar Value of Energy Savings for Selected Water-Saving Devices and Fuel Types ..........................

Table 4.1 Innovative Increasing Block Rates Schedule ...............

Table 4.2 Relative Frequency of Water Rate Schedule Types for a Sample

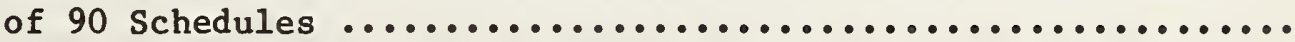

Table 4.3 Mean Values of Key Rate Schedule Variables for a Sample of 90 Schedules, by Household Size and Monthly Consumption .....

Table 4.4 Charges Unrelated to Consumption as a Percentage of Total Water Bill, by Household Size and Monthly Consumption .......

Table 5.1 Formulas for Discounting Future Values to the Present ....... 
CONVERSION FACTORS FROM CUSTOMARY TO METRIC (SI) UNITS

\begin{tabular}{|c|c|c|c|}
\hline Quantity & To Convert From & To & Multiply By \\
\hline Length & $\begin{array}{l}\text { Ineal foot (f) } \\
\text { inch }(1 n)\end{array}$ & $\begin{array}{l}\text { meter (m) } \\
\text { meter (m) }\end{array}$ & $\begin{array}{l}3.048 \times 10^{-1} \\
2.540 \times 10^{-2}\end{array}$ \\
\hline Area & square foot (sf) & square meter $\left(\mathrm{m}^{2}\right)$ & $9.290 \times 10^{-2}$ \\
\hline Volume & $\begin{array}{l}\text { cubic foot (cf) } \\
\text { gallon (gal) } \\
\text { quart (qt) }\end{array}$ & $\begin{array}{c}\text { cubic meter }\left(\mathrm{m}^{3}\right) \\
\text { liter }(\mathrm{L}) \\
\text { liter }(\mathrm{L})\end{array}$ & $\begin{array}{l}2.832 \times 10^{-2} \\
3.785 \\
9.461 \times 10^{-1}\end{array}$ \\
\hline Pressure & $\begin{array}{l}\text { pounds per square } \\
\text { inch ( } p s i)\end{array}$ & k1lopascal (kP) & 6.895 \\
\hline Price & dollars/gallon (\$/gal) & dollars/11ter $(\$ / L)$ & $2.641 \times 10^{-1}$ \\
\hline
\end{tabular}




\section{INTRODU CTION}

In the past few years water has begun to be regarded as a limited resource in many parts of the country. Many regions, particularly the Southwest, have experienced water shortages in more densely populated areas. In these areas, and wherever the possibility of future shortages has been anticipated, community water resource planners have taken measures to conserve water through public information programs and even mandatory restrictions. In response to these developments, a number of special plumbing devices designed to save water have recently become available on the market. Quite a few of the devices applicable to residences enable the homeowner to save water while still enjoying the same level of performance as before. Homeowners need to know whether the cost of a particular device will be offset by the value of the saved water and energy over the life of the device.

\subsection{PURPOSE}

The purpose of this report is to present an economic decision framework for utilities to use in recommending water-saving devices that are cost-effective for homeowners. To this end, the types of water-saving devices avallable for single-family residences are described. These devices are applicable to such indoor plumbing fixtures as showers, water closets, and faucets. They can be incorporated into a residence under one of two basic situations: (1) as an integral part of new construction, renovation, remodeling, or repair activities; or (2) purely for the purpose of reducing water consumption in an existing, otherwise unaltered, home. The former situation will be referred to as a new application; the latter as a retrofit application. The major components of costs and benefits resulting from the introduction of water-saving devices into residences are discussed for both new and retrofit applications. One of the most critical elements affecting the benefits of these devices is the price homeowners pay for water. Consequently, this report includes a detailed analysis of the rate schedules currently used by utilities to cover their costs. The report concludes by presenting an analysis framework for considering all the cost and benefit components and selecting the most cost-effective combination of water-saving devices.

\subsection{SCOPE}

The focus of this report is limited in several respects. First, only those devices applicable to indoor water use in single-family residences on individual water meters are considered. Water-saving devices that can be applied to agricultural or residential irrigation, industrial processes, or commercial buildings are excluded from the present focus. Secondly, even though utilities may recommend cost-effective water-saving devices, the final decisions to save water by installing these devices are assumed to be made by individual homeowners. Thus, the benefits and costs considered in the decision framework are those which are expected to accrue to and be borne by homeowners themselves. For example, the benefit of saving water is measured directly by the water rates paid by homeowners rather than by the costs incurred by utilities in supplying water. 
the third area that defines the scope of this report concerns which parameters are taken into account by the decision framework. The framework considers the major cost components: acquisition; installation; operation, maintenance, and repair; and replacement costs. On the benefit side, three major components are taken into account: water savings, avoidance of wastewater treatment, and energy savings due to the reduction of hot water use. The decision framework allows detailed specification of the actual prices homeowners pay at the local level for water, wastewater treatment, and energy for heating water. Moreover, the framework is flexible enough to accommodate the different treatments needed for the two cases of new and retrofit applications. In addition, the economic efficiency criteria embodied in the decision framework can address the two distinct situations of mutually exclusive and compatible devices.

\subsection{ORGANIZATION}

Section 2 describes a variety of conservation devices and provides estimates of their water-saving potential. The devices are classified under the following categories: water closet devices, shower devices, faucet devices, water-saving appliances, and miscellaneous devices.

Section 3 discusses water-conserving devices in terms of their costs and benefits. The cost components of water-saving devices are those costs associated with their acquisition, installation, operation, maintenance, repair, and replacement. The benefit components are concerned with the savings brought about by the use of conservation devices. Savings of water and energy are discussed, as are savings resulting from the avoidance of wastewater treatment.

Section 4 is concerned with the dollar value to homeowners of conserved water, as reflected in lower water bills. The various types of water rate schedules are explained. A national sample of 90 rate schedules is analyzed to provide a detailed picture of the appropriate price to be used for valuing water savings.

Section 5 presents the economic decision rules for utilities to use in recommending water-saving devices that are cost-effective for homeowners. The process of discounting future costs and benefits to their equivalent present values is explained and distinct decision criteria are given for mutually exclusive and compatible devices.

Section 6 provides a brief summary of the major findings of this research and offers some suggestions for implementing these results. 


\subsection{DESCRIPTION OF WATER CONSERVATION DEVICES}

This section provides a brief overview of the most common types of water-saving devices. In many instances, some measure of the amount of water saved through the use of a particular device is indicated. This section does not contain an exhaustive list of devices or detailed information on each device mentioned.1 It does, however, serve to lay the groundwork for specifying the methodology for selecting devices.

There are many different types of water conservation devices available, ranging in cost from a few pennies to several thousand dollars. These devices also vary in terms of their effectiveness in reducing the quantity of water consumed by households. The water conservation devices discussed in this report are classified under five categories. These categories are: (1) water closet devices; (2) shower devices; (3) faucet flow control devices; (4) water-saving appliances; and (5) miscellaneous devices. Table 2.1 lists each water conservation device discussed in this section under its appropriate category.

It is noteworthy that, for the most part, devices within each of the first three device categories of table 2.1 are mutually exclusive; that is, the devices perform the same basic function, so only one can be utilized with regard to a given fixture. In general, devices are compatible across categories, in that devices from several categories can be used in concert to reduce the overall water usage of a particular household. This distinction between mutually exclusive and compatible devices will play an important role in the application of the economic decision framework presented in section 5.

Table 2.2 shows the percentage of total indoor residential (domestic) water use corresponding to various water use functions. The two functions requiring the greatest amounts of water are Water Closet and Bath/Shower. Together, these water use functions account for 70 percent of total domestic water consumption.

\section{$2 \cdot 1$ WATER CLOSET DEVICES}

As indicated in table 2.2 , water used for waste removal through the toilet is the largest component of total household water use. The standard tank toilet

1 For more detailed information on a variety of water conservation devices and their water-saving potential, see J. Ernest Flack, Wade P. Weakley and Duane W. Hill, Achieving Urban Water Conservation: A Handbook, PB-278 174, prepared by Colorado State University for the Office of Water Research and Technology, Washington, DC, September 1977. In addition, many of the sources cited in this section (e.g., Feldman, 1977 and North Marin, 1977) provide detailed descriptions of water-saving devices. 
Table 2.1. Water-Saving Devices

Water Closet Devices

Plastic Bottle

Toilet Dam

Dual Flush Device

Weighted Tank Ball

Batch-Type Flush Valve

Improved Float Assembly

Shallow Trap Tollet

Pressurized Toilet Tank*

Compressed Air Tollet*

Vacuum Toilet*

011 Recycle Toilet*

Shower Devices

Shower Flow Control Valve

Flow Control Showerhead

Shower Flow Restrictor

Shower Cut-Off Valve

Automatic Shut-Off Valve

Thermostatic Mixing Valve

Pressure-Balancing Mixing Valve

Air-Assisted Shower*

Faucet Devices

Flow Control Faucet

Faucet Flow Control Valve

Faucet Flow Restrictor

Faucet Aerator

Spray Tap

Thermostatic Mixing Valve

Automatic Shut-off Valve

Water-Saving Appliances

Front Loading Washer

Varlable Water Level Control

Suds-Saver Feature

Dishwasher (cycle-adjusted)

Miscellaneous Devices

Hot Water Pipe Insulation

Pressure-Reducing Valve

* Specialty Devices 
Table 2.2. Percentage Distribution of Domestic Water Use by Function

\author{
Water Use \\ Function \\ Water Closet \\ Bath/Shower \\ Lavatory Sink \\ Drinking/Cooking \\ Laundry \\ Dishwashing
}

Total

\section{Percentage of \\ Total Domestic \\ Water Usea $(\%)$}

40

30

5

0

15

$\underline{5}$

100

Source: Flack, Weakley and Hill, p. 12 .

a The percentage distribution for domestic water use cited in this column is based on mean water use values for each function category from eight separate studies of household water use patterns. 
uses between five and seven gallons of water per flush.1 Clearly, the potential for saving water through the use of water closet devices is great.

Water closet devices can generally be classified under three headings:

(1) add-on items, which modify existing water closets; (2) replacement fixtures, which operate in the same manner as conventional toilets, but contain watersaving design features; and (3) specialty devices which operate in a manner different from that of conventional water closets, and often require complex and costly installation.

Add-on water closet devices are inexpensive and are often effective ways to reduce the amount of water used in waste removal. One of the simplest and least expensive devices consists of two plastic bottles filled with water and placed in the tank of a conventional toilet. The bottles should be weighted with small stones or other objects to keep them in place. This type of displacement device reduces the amount of water used to flush the toilet, while maintaining waste removal efficiency in the bow 1.2 Two one-quart plastic bottles can reduce water use per flush by 10 percent, saving about 2.5 gallons per capita per day (gpcd). 3

Toilet dams reduce the volume of water available for flushing by partitioning off a portion of the toilet tank. Such devices are relatively inexpensive and can produce savings of about $5 \mathrm{gpcd} .4$

Variable flush attachments permit the user to determine the duration of the flush cycle, and consequently, to reduce the quantity of water used per flush. Two types of variable flush attachments are the dual flush device and the weighted tank ball. Dual flush toilet devices allow the use of different flush cycles for the removal of solid and liquid wastes. The flush cycle for solids requires 3.5 gallons of water, while the liquid cycle may require as little as 1 gallon. In one model of the dual flush tollet a short turn of the flush handle is used for the liquid cycle and a more persistent turn for the solid cycle. Another model requires that the flush handle be turned in one

1. California Department of Water Resources, Water Conservation in California, Bulletin No. 198, Sacramento CA, May 1976, p. 18.

2 S.L. Feldman, A Handbook of Water Conservation Devices, Clark University NSF/RANN Grant No. Apr-76-19369, November 1977, p.9. In some cases, however, reduced wastewater flows have caused blockages in horizontal drain pipes. J.W. Bishop, "Field Experiences in Water Savings Programs of the Washington Suburban Sanitary Commission," Proceedings of the Conference on Water Conservation and Sewage Flow Reduction with Water Saving Devices, Pennsylvania State University, University Park, PA, Apri1 8-10, 1975.

3 North Marin County (California) Water District, North Marin's Little Compendium of Water Saving Ideas, North Marin, CA, August 1976, p. 44.

4 Ibid. 
direction when less water is needed and in the other for a larger volume flush. 1 A 1974 study indicates that the dual flush toilet saves about 3.3 gpcd. 2 Recommendations for a standard to assure the efficient operation of these dual flush devices have already been developed. 3 The other variable flush device involves increasing the weight of the tank ball. A weighted tank ball permits the user to adjust the flush cycle by holding down the flush handle for as long as is necessary to clear the bowl of waste materials. This variable flush attachment can save approximately 5.4 gpcd. 4

Batch-type flush valves provide more forceful water flushing than conventional water closets by means of an oversized feed line and a quick release valve.5 These devices can be set to operate at between 0.5 and 4 gallons, with 3 to 4 gallons being the usual setting. 6 Water savings from flush valves have been estimated at 7.5 gpcd. 7

Improved float assemblies allow easy adjustment of the tank level. The improved design of this device eliminates the float and rod arm. Water savings result because water in the toilet tank can be set at a level which provides maximum flushing efficiency. 8

The most common type of water-saving replacement fixture is the shallow trap toilet. It operates in the same manner as a conventional water closet, but conserves water due to its smaller tank volume and special bowl design. The shallow trap toilet uses about 3.5 gallons of water per flush, as compared with

1 Carol Hupping Stoner, ed., Goodbye to the Flush Toilet, Rodule Press, 1977, p. 240 .

2 Sheldon Cohen and Harold Wallman, Demonstration of Waste Flow Reduction from Households, EPA-670/2-74-071, September 1974, p. 4 .

3 Fred Winter and Lawrence S. Galowin, Criteria and Evaluation for Two-Step Flush Devices for Water Closets, National Bureau of Standards Interagency Report 81-2296, Washington, DC, June 1981.

4 Cohen and Wallman, p. 4.

5 North Marin, p. 38.

$6 \mathrm{~J}$. Crisp and A. Sobolev, "An Investigation of the Performance of Lavatories Using Spray Taps and of Sanitary Accomodation in an Office Building," Journal of the Institution of Water Engineers, Vo1. 13 (1959), pp. 513-525.

7 James R. Bailey, et al., A Study of Flow Reduction and Treatment of Waste Water from Households, prepared by General Dynamics for the Federal Water Quality Administration, Washington, DC, December, 1969, p. 62 .

8 University of Illinois at Urbana-Champaign, "Water Conservation," Council Notes, Vo1. 2, No. 3 (Winter 1977), p. 7. 
the 5 to 7 gallons per flush used by the standard toilet.1 It is significant to note that a shallow trap tollet permits savings of $7.5 \mathrm{gpcd}$ and costs only slightly more than a conventional fixture.2

Speclalized types of water closets tend to be relatively expensive, but they offer the greatest potential for water savings. It should be noted that these devices may be most applicable in locations where conventional means of wastewater disposal are unavallable. Furthermore, such specialty devices may be in violation of local bullding regulations.

A pressurized tollet tank uses air pressure to assist water in flushing the bowl. This device replaces the standard tollet tank and can completely clean the bowl with only 2.5 gallons of water. 3 A compressed air toilet combines gravity and air pressure propulsion ( $50-70 \mathrm{psi}$ ) in the flushing action. This device uses about 0.5 gallons of water per flush, thus saving about 90 percent of the water used by a conventional tollet. 4 The vacuum tollet system uses specially designed tollets, sewage pipes, and storage tank. The system is designed for installation in a group of residences. Its operation requires only about 1.3 quarts of water and 3.25 cublc feet of air per flush. One drawback of these water closets that use a $\frac{1}{5}$ pressure in the flush is that energy is needed to produce the air pressure. 5

The ofl recycle tollet (also called oll carriage tollet and o1l flush tollet) uses oil instead of water as a recirculating medium. The system separates the oll from waste materials, filters 1 , and recycles it to the tollet. It saves all the water used by a conventional tollet.

The foregoing is not an exhaustive list of specialty water closet devices.6 Several devices are omitted due to problems of ultimate waste disposal and their general lack of public acceptance.

1 Stoner, p. 239.

2 North Marin, p. 44.

3 stoner, p. 240.

4 Feldman, p. 6.

5 Murray Milne, Residential Water Conservation, California Water Resources Center, University of California at Davis, Report No. 35, March 1976, pp . 197-200.

6 For an excellent description of the wide range of specialty water closet systems available, see Milne, pp . 165-232. 


\subsection{SHOWER DEVICES}

About forty percent of the hot water consumed in residences is used for bathing, and this activity accounts for about 30 percent of all household water use. The normal shower has a flow of from five to ten gallons per minute (gpm) when fully opened. 1 The rate of water flow through showers may be reduced by (1) adding a water-saving device to an existing showerhead; (2) replacing the showerhead with a water-saving unit; or (3) replacing the existing shower plumbing with a specialty system.

Care should be taken in interpreting the figures given for water savings through the use of shower devices. Shower duration and intensity can greatly affect the water-saving potential of these devices. These factors vary widely among individuals. It is, therefore, difficult to estimate the savings resulting from water-conserving shower devices.

Shower flow control devices reduce the flow of water through the showerhead by creating a smaller opening in the water line. There are three types of shower flow control devices. Shower flow control valves are fitted upstream of an existing showerhead. Flow control showerheads are replacement showerheads that have been estimated to save 10 gpcd. 2 The shower flow restrictor is inserted directly into the pipe upstream of the showerhead. Savings of 5 gpcd have been reported for this type of shower flow control device. 3

There are two devices which operate by curtailing flow duration, and thereby reduce water consumption. Shower cut-off valves allow shower water to be turned on and off by the user without touching the temperature controls. Thus, the user can save water by turning off the shower while lathering. This device can be either an add-on device or an integral part of a replacement showerhead. The automatic shut-off valve prevents water wastage by acting as a self-closing shower valve. This device is primarily applicable in an institutional setting.

Thermostatic mixing valves are useful water savers because they eliminate water warm-up time and the need for readjustments due to changes in water temperature. This device maintains a selected water temperature level and offers potential savings of 2.0 gpcd. 4 Pressure-balancing mixing valves maintain water pressure

1 Cohen and Wallman, p. 31. It should be noted that flow rates as high as $15 \mathrm{gpm}$ have been reported. See Feldman, p. 28.

2 Wallace J. Hopp and William P. Darby, "Household Water Conservation: The Role of Indirect Energy Savings," Energy: The International Journal, Vol. 7 , No. 3 (December 1980), p. 1185.

3 Ibid.

4 Balley, et al., p. 62 . 
and can thereby reduce water wastage. Pressure-balancing valves, however, only correct for fluctuations in water pressure and do not compensate for variations in supp $1 y$ temperature.1

The air-assisted shower is the only specialty system avallable for showering. The system consists of a specially designed showerhead and an air compressor which may be mounted either above the celling or behind the wall of the shower stall. A mix of compressed air and water at the showerhead produces a spray with full stream effect while reducing water use to as little as $0.5 \mathrm{gpm} .2$

\subsection{FAUCET DEVICES}

Normal residential faucet flow rates are between 5 and $8 \mathrm{gpm}$ when fully opened. Faucet flow control devices operate in the same manner as shower flow control devices, and are of the same three types. A flow control faucet is a replacement faucet that reduces the flow rate to between 0.5 and $2.5 \mathrm{gpm} .3$ Savings of $0.5 \mathrm{gpcd}$ can be achieved for each faucet utilizing this device.4 A faucet flow control valve is a pipe fitting that screws onto the pipe upstream of the faucet. A faucet flow restrictor is inserted directly into the lead-in pipe. The faucet flow control valve and restrictor both reduce the flow rate to $4 \mathrm{gpm}$ or less. 5

Faucet aerators reduce the amount of water flowing through the faucet by introducing air into the flowing stream of water. Flow rates vary among different models of faucet aerators, but are generally about $2.5 \mathrm{gpm} .6$ Savings of $0.25 \mathrm{gpcd}$ per faucet have been reported for this device.7 Spray taps deliver a broad pattern of droplets similar to the flow of a showerhead. Other waterconserving faucet devices are the thermostatic mixing valve and the automatic shut-off valve. Each of these devices yields small water savings when used in conjunction with bathroom and kitchen faucets.

In addition to saving water, the faucet and shower devices previously mentioned can potentially save significant amounts of energy by reducing hot water use. This matter will be discussed in greater detail in section 3.2 .3 .

1 Milne, p. 251 .

2 Ibid., p. 25.

3 North Marin, p. 77.

4 Bailey, et al., p. 62 .

5 North Marin, p. 82 .

6 Flack, Weakley, and Hill, p. 58.

7 Hopp and Darby, p. 1185. 


\subsection{WATER-SAVING APPLIANCES}

The principal household water-using appliances are the clothes washer and dishwasher. Laundering and dishwashing account for about 20 percent of total domestic water use (see table 2.2), and over 35 percent of water heating energy consumption. 1

Water requirements for clothes washers range from 38 to 69 gallons per cycle.2 Front loading washers use 30 to 50 percent less water than top loaders for equivalent loads. 3 The variable water level control and the suds-saver are two water-saving features available on automatic clothes washers. The variable water level control allows, the user to adjust the quantity of water used by the machine according to need." The suds-saver option permits the reuse of laundry wash water for additional loads. A utility or service sink is required for water storage. Wash water savings of about 25 percent have been estimated when utilizing the suds-saver feature. 4

Dishwashers use from 12 to 18 gallons of water per cycle. Adjustment of the dishwasher cycle can lead to significant water savings. Dishwasher cycle adjustment is estimated to save from 7.5 to 12.5 gallons per cycle in some models. 5

\subsection{MISCELLANEOUS DEVICES}

Some water-saving devices are not directly applicable to water closets, showers, faucets, or specific appliances. Two such conservation devices are hot water pipe insulation and pressure-reducing valves. Hot water pipe insulation reduces water consumption by retaining heat in water for longer periods in the distribution pipes, thereby lessening the time spent waiting for hot water after the tap (faucet or shower) is turned on. Insulation is estimated to result in savings of $2 \mathrm{gpcd} .6$

1 Robert L. Palla, Jr., The Potential for Energy Savings with Water Conservation Devices, National Bureau of Standards Interagency Report 79-1770, Washington, DC, September 1979, p. 11 .

2 "Washing Machines," Consumer Reports, October 1975, pp • 611-615.

3 Robert L. Palla, Jr., Water Usage Characteristics of Household Appliances and the Potential for Water Savings, Center for Consumer Product Technology, National Bureau of Standards, Washington, DC, December 1979, p. 8.

4 Ibid.

5 Estimate based on a survey conducted by the Washington Suburban Sanitary Commission.

6 North Marin, p. 30 . 
pressure-reducing valves are generally installed in main water supply lines. These valves reduce the water pressure, and thus the rate of water flow through all household fixtures and appliances. Reported water savings resulting from pressure-reducing valves differ significantly because of supply pressure variations. In one test program involving conventional appliances, water supply pressure was reduced from 80 to 50 psi, resulting in water savings of up to 30 percent. 1 Note, however, that when pressure-reducing valves are used in conjunction with other water conservation devices, the lower water pressure may substantially reduce the water-saving potential of the devices.

Estimates of the water-saving potential of a wide range of devices have been provided in this section. Water-conserving capability, however, is only one factor in developing a framework to evaluate the economic efficiency of watersaving devices. Information regarding the costs and other benefits of watersaving devices is also required.

1 Feldman, p. 45. 


\section{COST AND BENEFIT COMPONENTS OF WATER-SAVING DEVICES}

In order to develop a decision framework regarding the economic efficiency of residential water-saving devices, it is necessary to evaluate the costs and benefits resulting from the use of such devices. The costs associated with water-saving devices can be of four types: (1) acquisition costs; (2) installation costs; (3) operation, maintenance, and repair costs; and (4) replacement costs. It should be noted that one or more of these cost components may not be applicable to a number of water conservation devices. The benefits resulting from the use of these devices include the savings from reduced water consumption and wastewater treatment, as well as energy savings.

\subsection{COST COMPONENTS}

In this section, cost information is provided on many of the water conservation devices listed in table 2.1. The figures cited here are approximate costs based on data from a variety of studies within the last six years. Unless otherwise noted, no attempt was made to update these costs. Although not all cost components for all devices are covered, the information does illustrate the order of magnitude and type of cost data required for an analysis of such devices. This section also identifies special costs which are applicable to particular devices, and indicates the types of costs included in each of the four cost components.

\subsubsection{Acquisition}

The acquisition costs related to water-saving devices can range from nothing to several thousand dollars. In general, the cost of add-on devices (e.g., plastic bottles, toilet dams, shower flow restrictors) is considerably less than that of replacement fixtures. Unless otherwise stated, the acquisition cost component of water conservation devices indicated in this section represents the cost to the consumer of materials only.

It is important to distinguish between the cost of water-conserving devices installed in new applications and the cost of those installed in retrofit applications. An example of the costing rules for new and retrofit applications is provided by the shallow trap toilet. The acquisition cost attributable to a fixture installed in a new application is the differential cost between the fixture with the water-saving feature and the equivalent conventional fixture without the feature. Thus, since a shallow trap toilet costs $\$ 70$, and a conventional toilet $\$ 60,1$ the acquisition cost of a shallow trap toilet in a new application is $\$ 10$ (1.e., $\$ 70-\$ 60) .2$ In contrast, the same device used in a retrofit application would cost considerably more. In this case, the proper acquisition cost is the entire cost associated with acquiring the device. The acquisition cost for the shallow trap toilet in a retrofit

\footnotetext{
1 Feldman, p. 2 .

2 Milne, p. 180.
} 
application, therefore, is $\$ 70$. Note that since an add-on device has no conventional counterpart, its acquisition cost is always its entire cost. In general, the acquisition costs cited in this section are the costs associated with acquiring the conservation fixture in a retrofit application. Table 3.1 lists most of the acquisition costs cited in this section for devices used in retrofit applications.

One of the least expensive water-saving devices for a tollet consists of two plastic bottles placed in the tank. Two one-quart plastic bottles can be purchased for $\$ 0.90 .1$ An appropriate substitute for the commercially available variety can generally be salvaged from the household waste stream at no cost. Toilet dams reduce the amount of water used in flushing by sectioning off a portion of the tank. They cost about $\$ 6$ each and are available from several manufacturers.2 A dual flush device permits the use of different amounts of water for the removal of liquid and solid wastes. This device, which is added onto an existing toilet, costs about $\$ 16.3$ A weighted tank ball, which allows the user to select the length of the flush cycle by depressing the flush handle for the amount of time required to clear the bowl, costs about $\$ 5.4$

The acquisition costs of specialized water closets are for the most part significantly higher than those of conventional fixtures. A pressurized toilet tank can be installed on almost any standard two-plece toilet. It provides a high velocity flush, is operated by a push button, and costs about $\$ 60$. The compressed air toilet, which flushes through a combination of gravity and air pressure propulsion, has material costs of about $\$ 300$ for the toilet and $\$ 60$ for the small air compressor.5 The vacuum toilet system is installed to serve a number of residences and uses suction to transfer waste into a shared storage tank. Thus, the cost of the system per residence depends upon such factors as the number of residences on the system, housing density, and soil and terrain characteristics. 6

The oil recycle toilet is a relatively expensive speclalty water closet device. It uses 20 to 30 gallons of mineral oil to transport and deposit waste materials. This oil is filtered and recycled with each flush and need never be replaced. Waste materials can be deposited in a storage tank for yearly removal or incinerated. One source reports the acquisition cost of the ofl recycle toilet to

1 Ibid., p. 232.

2 North Marin, p. 44.

3 Milne, p. 230.

4 Feldman, p. 5.

5 Ibid., pp . 6-8.

6 Milne, pp . 206-207. 
Table 3.1 Acquisition Costs of Selected Water-Saving Devices Used in Retrofit Applications

Type of Device

Acquisition

Cost $(\$)$

Water Closet Devices

Plastic Bottles (2)*

Toilet Dam*

Dual Flush Device*

Weighted Tank Ball*

Shallow Trap Toilet

Pressurized Toilet Tank*

Compressed Air Toilet

Shower Devices

Flow Control Showerhead

Shower Flow Restrictor*

Shower Cut-0ff Valve

Thermostatic Mixing Valve

Pressure-Balancing Mixing Valve

Air-Assisted Shower

Other Devices

Faucet Flow Restrictor*

Faucet Aerator*

Thermostatic Mixing Valve (Faucet)

Hot Water Pipe Insulation ( $\$ / f$ )

Pressure-Reducing Valve
0.90
6.00
16.00
5.00
70.00
60.00
60.00

8.00

1.50

13.00

60.00

45.00

270.00

1.00

3.00

60.00

0.50

22.00

Sources: Larry K. Baker, Harold E. Bailey and Raymond S. Sierka, "Household Water Conservation Effects on Water, Energy and Wastewater Management," Proceedings of the Conference on Water Conservation and Sewage Flow Reduction with Water Saving Devices, Pennsylvania State University, University Park, PA, April 8-10, 1975, p. 78; Feldman, pp. 2, 5, 6-8, 31-32; Hopp and Darby, p. 1185; Milne, pp - 230, 232, 243, 249, 252, 289-291; North Marin, PP. 44, 105; and conversations with manufacturers.

* Acquisition costs of these devices assume they are added onto the existing plumbing fixture. 
be about $\$ 2500$ (without incinerator).1 A manufacturer indicates that the device may cost $\$ 6,000-86,000$ depending on capacity (600-20,000 gallons per day) and whether an incinerator is included.2 The oil recycle toilet is most practical for large-scale installations.

Flow control showerheads resemble standard showerheads while offering water savings. These devices cost 15 to 20 percent more than conventional fixtures, but are still relatively inexpensive at less than $\$ 10$ each. 3 shower flow restrictors inserted upstream of the showerhead cost only $\$ 1$ or $\$ 2.4$ 0ccasionally, flow restrictors are provided free of charge to homeowners by utilities.5

Shower cut-off valves permit the water flow to be shut off and on without readjustment of the temperature controls. One showerhead model containing this feature costs about $\$ 13.6$ The valve itself, which can be fitted on the lead-in pipe upstream of most standard showerheads, costs a couple of dollars.7

A thermostatic mixing valve allows the mixing of hot and cold water to pre-set temperatures. This device can be used in conjunction with showers and bathtub and sink faucets. It costs about $\$ 60-$ considerably more than conventional valves.8 Pressure-balancing mixing valves adjust for changes in water pressure, thereby maintaining the desired water pressure. At a cost of about $\$ 45$, this device is approximately twice the cost of a standard valve.9

The air-assisted shower, a specialty shower system, mixes air and water to create a water-conserving spray which gives the sensation of a full shower. With an acquisition cost of about $\$ 270,10$ it is far more expensive than other water-saving shower devices.

1 Ibid., p. 198.

2 Feldman, p. 16.

3 Ibid., p. 29.

4 North Marin, p. 105.

5 Milne, p. 240.

6 Feldman, pp . 31-32.

7 North Marin, p. 113.

8 Milne, p. 249.

9 Ibid., p. 252.

10 Baker, et al., p. 78 . 
A faucet flow restrictor is inserted in the pipe upstream of the faucet to reduce the flow of water. This device retails for about $\$ 1.00 .1$ Faucet aerators reduce water usage by introducing air bubbles into the water stream. The device is an integral part of all new faucets, so its cost is included in the initial cost of the fixture. The cost of an add-on aerator ranges from $\$ 1$ to $\$ 5.2$

Front loading clothes washers use considerably less water and detergent to wash equivalent loads than do top loading washers. Front loading machines, however, are significantly more expensive than the top loading variety. 3 Two watersaving features, the variable water level control and the suds-saver option, are available only as original equipment on clothes washers. The cost of the variable water level control cannot be clearly separated from the cost of the entire washer unit, while the suds-saver option adds about $\$ 20$ to the cost of a clothes washer. 4 In addition, the acquisition cost component of the suds-saver feature is significantly increased if the user does not already have the utility or service sink required for wash water storage.

At a cost of about $\$ 0.50$ per lineal foot of pipe, hot water pipe insulation saves water by reducing the waiting time required for water to warm up. Pressure-reducing valves are usually installed in the main water supply lines. They reduce unnecessarily high pressures to a lower level and are available for about $\$ 22.5$

\subsubsection{Installation}

The installation component of costs related to water conservation devices is essentially the cost of labor required to put the device in service. Materials used in installation are considered part of the acquisition cost component. often the installation of a water-saving device requires little time, and no specialized knowledge or equipment. In such cases the homeowner is easily able to install the device and its installation cost can be assumed to be zero. Table 3.2 lists water conservation devices which could be considered to have a zero installation cost component.

The nature and/or installation location of several water-saving devices is such that they have significant costs related to their installation. The services of a professional installer (e.g., plumber) are frequently necessary due to the complexity of these devices and the special equipment they require.

1 Conversation with manufacturer.

2 Milne, p. 243.

3 Robert L. Palla, Jr., Water Usage Characteristics of Household Appliances and the Potential for Water Savings, P. 8 .

4 Milne, p. 284.

5 Ibid., pp. 289-291. 
Table 3.2 Selected Water-Saving Devices that Homeowners could Install, Operate, and Maintain at No Financial Cost

\author{
Plastic Bottles \\ Tollet Dam \\ Dual Flush Device* \\ Weighted Tank Ball \\ Flow Control Showerhead \\ Shower Flow Restrictor \\ Shower Cut-off Valve \\ Faucet Flow Restrictor \\ Faucet Aerator \\ Hot Water Pipe Insulation
}

Sources: Hopp and Darby, p. 1185; North Marin, 1977; Feldman, 1977; and William Sharpe, Water Conservation and Wasteflow Reduction in the Home, Special Circular 184, Pennsylvania State University, April 1974.

* In some cases, the services of a plumber may be required to install this device. Installation time would be less than one hour, so the installation cost would be less than $\$ 22.35$ based on the average wage rate for plumbers. See R. S. Means Co., Inc., p. 291. 
Although the installation of some devices in remote areas may include significant transportation costs, it must be noted that the installation cost figures cited in this section are basically labor charges. Also important is the fact that plumbers may charge a $\$ 20$ to $\$ 30$ minimum fee for making a house call regardless of the difficulty of the job. This type of charge can greatly increase the installation cost component of some water-saving devices.

As was the case with the acquisition cost component, devices installed in new applications generally have a different installation cost component than devices installed in retrofit applications. Following the principle used above for acquisition costs, the cost of installing a water-saving device in a new application is the difference between the cost of labor necessary to install the conservation device and that required to install conventional hardware. In a retrofit application, the installation cost component represents the total cost of labor utilized. The batch-type water closet flush valve can be used to illustrate the differing costs applicable to installing water-saving devices in new versus retrofit applications. The installation cost component for this device in a new application is about $\$ 45$, and in a retrofit application approximately $\$ 90.1$

Table 3.3 presents the installation costs of various devices for both new and retrofit applications. Note that the shallow trap toilet and thermostatic mixing valve both have zero installation costs when used in new applications. This is because there are no additional installation costs attributable to the water-saving features of these fixtures. In both new and retrofit applications, the installation cost for a pressure-reducing valve is the total installation cost because this device does not replace conventional hardware.

\subsubsection{Operation, Maintenance, and Repair}

The operation, maintenance, and repair (OMR) component of costs associated with water-saving devices is composed of two basic cost factors. The first factor includes costs arising from the day-to-day operation of a device. This factor covers all energy or fuel costs related to water-saving devices, as well as various special materials required for the proper operation of some devices (e.g., the mineral oil required to operate the oil recycle toilet). The second factor is the cost of maintaining a device in proper functioning condition. This includes any maintenance services or repairs which might reasonably be expected to be required during the lifetime of a particular device.

1 The installation cost figures cited were taken from Bailey, et al., 1969, p. 62 , and have been updated based on the 1980 wage rate for plumbers listed in R. S. Means Co., Inc., Building Construction Cost Data 1980, 38th annual edition, Kingston, MA, 1979, p. 291. A labor rate of $\$ 7.50$ per hour is indicated in Bailey, et al., p. 59. This rate served as the basis for the 1969 installation costs. The updated wage rate ( $\$ 22.35$ per hour) includes fringe benefits, overhead, and profit, and represents an average of plumbers' wages in the 30 largest U.S. cities. 
Table 3.3 Installation Costs (\$) of Selected Water-Saving Devices Used in New and Retrofit Applications

\begin{tabular}{lcc}
\hline & \multicolumn{2}{c}{ Application } \\
\cline { 2 - 3 } Device & New & Retrofit \\
Batch-Type Flush Valve & 45 & 90 \\
Shallow Trap Toilet & 0 & 50 \\
Compressed Air Toilet & 195 & 245 \\
Thermostatic Mixing Valve & 0 & 10 \\
Air-Assisted Shower & 50 & 150 \\
Pressure-Reducing Valve & 10 & 10 \\
\hline
\end{tabular}

Sources: Bailey, et al., pp. 59, 62; Baker et al., pp. 77-78; Hopp and Darby, pp. 1184-1185; and R. S. Means Co., Inc., p. 291. 
The water-saving devices listed in table 3.2 could be operated and maintained without the homeowner incurring any financial expense. The shallow trap toilet has OMR costs of about $\$ 5$ every five years. Operation and maintenance costs associated with the oil recycle toilet total about $\$ 40$ per year.1 It costs about $\$ 0.60$ per year to operate and maintain the one-sixth horsepower compressor of a compressed air toilet. An air-assisted shower costs approximately $\$ 1.95$ per year to operate and maintain.2

In examining OMR costs related to water-saving devices it is important to take note of the number of years a particular device is expected to remain in working order. Water-conserving fixtures generally require only minimal maintenance to remain in working condition for a long period of time. Table 3.4 lists several water-saving devices and their expected lifetimes.

\subsubsection{Replacement}

Whether replacement costs are incurred depends on the expected lifetime of the device relative to the length of the homeowner's planning horizon. Given the expected lifetimes of the devices listed in table 3.4, a planning horizon of 15 years would mean that none of these devices would have to be replaced. To the extent that such water-saving devices are fully functional in and of themselves and thus totally independent of an existing fixture, they will most probably have no replacement cost component over a 15 year period. Examples of such devices include the flow control showerhead, shallow trap toilet, and oil recycle toilet.

Add-on water-saving devices are attached to or associated with existing fixtures. The replacement cost of an add-on device is therefore dependent to some extent on the condition of the existing equipment. If the existing fixture does not break down over the 15 year period following the installation of the water-saving device, then the replacement cost with regard to the watersaving device will most likely be zero. If, however, the existing fixture does break down during the planning horizon period, a replacement cost may or may not be applicable to the water-saving device. The replacement cost component in this situation will equal zero only if the existing fixture is replaced with another conventional (non water-saving) fixture and if the water-saving device is in good working order, can be used in the new fixture, and no installation costs are involved in transferring the device to the replacement fixture. Perhaps more likely, the existing fixture will be replaced with a water-saving fixture which supplants or eliminates the need for the water-conserving add-on device. In this circumstance there would be a non-zero replacement cost component whose magnitude would equal the difference between the acquisition cost of the replacement water-saving fixture and that of its conventional counterpart. An example of a relatively small replacement cost is the case in which a conventional showerhead and an add-on flow restrictor are replaced by an integral

1 North Marin, p. 59.

2 Baker, et al., pp. 77-78. The operation and maintenance cost figures for the air compressor and air-assisted shower assume charges of $\$ .04 /$ kilowatt hour. 
Table 3.4 Expected Lifetimes of Selected Water-Saving Devices

Device

Plastic Bottles

Tollet Dam

Shallow Trap Tollet

011 Recycle Tollet

Shower Flow Control Valve

Flow Control Showerhead

Faucet Aerator

\section{Life (years)}

25

25

25

15

15

15

15

Source: North Marin, p. 59. 
flow control showerhead. The replacement cost component is the difference between the costs of the conventional and replacement (water-saving) showerheads, or less than $\$ 2.00$. An example of a relatively large replacement cost is the case in which a conventional toilet with a retrofit device (e.g., toilet dam or weighted tank ball) is replaced by a specialty water closet device such as the compressed air toilet. In this case, the replacement cost is the difference between the costs of the conventional and specialty toilets, or about $\$ 300.1$

\subsection{BENEFIT COMPONENTS}

Significant benefits can accrue to homeowners from the use of water-conserving devices in residences. Three major benefits -- water savings, wastewater treatment avoided, and energy savings - are discussed in this section.

\subsubsection{Water Saved}

The water that is saved is, of course, the most obvious benefit to be derived from the use of conservation devices. Recent growth in the demand for water has placed a strain on the water storage and supply capacity of many localities. In addition, most areas of the country have already developed their most easily exploitable sources of water. These areas must develop more complicated and costly alternative water sources or face the possibility of severe water shortages in the face of increasing demand. The use of water-saving devices reduces the rate of growth in demand for water and thus the costs of developing and utilizing alternative water sources.

In discussing the water-saving benefit arising from the use of conservation devices, it is necessary to determine the value of such a benefit. The value of water savings is a function of both the quantity of water saved and the value of each unit of water saved.

The quantity of water actually saved by a household through the use of water-saving devices is primarily a function of the types of devices used, the number of persons in the household served by the devices, the frequency with which the devices are used, the intensity of their use (e.g., how much time members of a particular household spend showering), and even the local water pressure. Estimates of typical water savings cited in various literature sources are reported in section 2 for some of the devices discussed there. Table 3.5 presents these estimates for purposes of illustration.

The value attributed to each unit of water saved depends on the point of view of the decision maker. Because this report assumes that the final decisions to save water are made by homeowners, the benefits derived from water-saving devices must be evaluated from the homeowner's viewpoint. The value a homeowner receives from reducing water consumption is reflected in lower water bills. Each unit of water saved is valued at the price the homeowner would have to pay for the water as specified by the rate schedule used by the water utility.

1 Feldman, pp. 6, 29. 
Table 3.5 Estimated Water Savings of Various Devices

Device

Plastic Bottles (2-1 qt)

Toilet Dam

Dual Flush Device

Weighted Tank Ball

Batch-Type Flush Valve

Shallow Trap Tollet

Flow Control Showerhead

Shower Flow Restrictor

Thermostatic Mixing Valve

Flow Control Faucets (2)

Faucet Aerators (2)

Hot Water Pipe Insulation
Savings

(gped)

2.5

5.0

3.3

$5 \cdot 4$

7.5

7.5

10.0

5.0

2.0

1.0

0.5

2.0

Sources: Bailey, et al., p. 62; Cohen and Wallman, p. 4; Hopp and Darby, p. 1185; and North Marin, pp. 30, 31-32, 44. 
A detailed study of rate schedules and the appropriate price to be used for valuing saved water is presented in section 4.

A hypothetical example will illustrate how the value of water saved through the use of conservation devices is calculated from a homeowner's point of view. If a household of four uses one tollet dam, one flow control showerhead, two flow control faucets, and hot water pipe insulation, then from table 3.5 , each household member is estimated to save a total of 18.0 gallons per day (gpd). Assuming the appropriate price for valuing saved water for a household of four is $\$ 0.78$ per 1000 gallons, 1 the reduction in the water bills for a year is calculated as follows:

$\$ .00078$ (saved water price per gallon) $\times 18.0$ (gpcd of water saved) $\times 4$ (household size) $\times 365$ (days per year) $=\$ 20.50$ (yearly value to homeowner of water saved).

It must be noted that the simultaneous adoption of water-saving practices by a large proportion of households may cause the utility to charge more money on average per unit of water consumed in the short run. Under certain water rate schedules, particularly those with increasing block rates, the reduced revenue resulting from water conservation efforts may be insufficient in the short run to cover the fixed costs incurred by the utility in supplying water. Under these circumstances, the short run dollar savings obtained by households would be less than if the rate schedule remained the same. In an extreme case, it is possible that some households (those which saved less water than the average reduction for the community) may end up with increased water bills, as happened in Marin County, California during the 1977 drought. In the longer run, however, it is expected that utilities can adjust their capacity by not replacing retired plant and equipment, and thus reduce the fixed costs of supplying water.

\subsubsection{Wastewater Treatment Avoided}

A major benefit of water-saving devices in dwellings is the reduced need for wastewater treatment. In the United States, about 26 billion gallons of wastewater are used daily to transport unwanted materials away from homes, businesses, and industries. Both organic and inorganic compounds can be found in wastewater either as suspended solids or dissolved in the water. 2 When wastewater is left untreated for some time there are several undesirable results. First, organisms that feed upon organic and inorganic compounds deplete the amount of oxygen present in the water, which in turn reduces the amount of

1 This is the average value of the prices charged for the last units of water consumed in four-person households, based on a national sample of 90 water rate schedules. This sample is analyzed in detail in section 4.

2 U.S. Environmental Protection Agency, Office of Water Program Operations, Determining Wastewater Treatment Costs for Your Community, Washington, DC, October 1979, p. 2 . 
aquatic life the water can support. In addition, some inorganic materials (e.g., phosphorus and nitrogen) cause odor problems as well. And finally, untreated wastewater often contains harmful microorganisms (e.g., typhus and polio) and high levels of chemicals suspected of causing human illnesses (e.g., mercury, lead, cadmiun, and zinc). Because of these problems, wastewater treatment is necessary to protect fish and wildife, and to prevent the spread of disease. 1

There are three basic levels of wastewater treatment: primary, secondary, and advanced treatment. Primary treatment removes readily settling and flotable materia]. Secondary treatment removes pollutants dissolved in water and provides more efficient removal of suspended solids. Advanced treatment removes phosphorus, nitrogen, and suspended solids. Under the Clean Water Act of 1977, all wastewater treatment plants must have at least secondary treatment.

Secondary treatment, the minimum requirement, provides an environment which encourages the natural treatment process of microorganisms feeding on organic matter in the water. Lagoons, large shallow wastewater ponds in which a biological community feeds on organic matter, represent a common secondary treatment method. Activated sludge processes use a tank in which there is enough oxygen to support a biological community. Another treatment method, trickling filters, operates by spraying wastewater onto rocks or plastic media to which microorganisms that feed on the wastewater are attached. 2

Several factors determine the type of wastewater treatment used in a particular area. These factors include climate, land availability, waste constituents, water quality criteria, general community goals, and the reliability and cost of a given treatment process. It is noteworthy that most of the wastewater treated at sewage treatment plants is attributable to the infiltration of ground water into sewer lines (often 30 percent of waste $\mathrm{flow}^{3}$ ) and to industrial waste flow. The quantity of sewage attributable to household waste flows is, therefore, relatively small.

Nevertheless, residential use of water-saving devices may significantly affect the wastewater treatment charges paid by homeowners. In many communities, a fixed periodic charge is levied for sewage treatment. In some others, sewer charges are directly related to water consumption as measured by periodic water meter readings. In addition to these periodic charges for sewer service, new homes are subject to a large lump-sum sewer connection charge.

1 Ibid., pp. 2-3.

2 Ibid., pp. 5-6.

3 A.J. Fowell, et al., "Water and Water-Related Conservation in Buildings," presented at USNCCIB/CIB International Symposium on Water Supply and Drainage, National Academy of Sciences, Washington, DC, September 28-30, 1976. 
A reduction in wastewater flows to an existing treatment plant can yleld considerable economic savings. These savings are in the form of decreased annual operating and maintenance (O\&M) costs. Table 3.6 presents national averages of annual $0 \& M$ costs for a non-lagoon secondary treatment plant according to the wastewater flow rate. For example, the $0 \& M$ costs for a plant handing a flow rate of 2.5 million gallons per day (mgd) are $\$ 205,000$. If it is assumed that 50 gallons per capita per day (gpcd) of wastewater are generated, this plant could serve the household needs of a community of 50,000 (2.5 mgd/50 gpcd). Now consider the effect of a wastewater flow reduction of 20 percent, to $40 \mathrm{gpcd}$, through the use of water-saving devices. This would reduce the flow rate to $2.0 \mathrm{mgd}(40 \mathrm{gpcd} \times 50,000)$. For the same quality of wastewater, such a flow rate reduction would lead to savings in annual 0\&M costs of $\$ 25,000$ $(\$ 205,000-\$ 180,000$, table 3.6).1 However, because the amount of household waste carried by the reduced water flow would remain the same, there would be no savings in treatment chemicals, which account for 7 percent of annual $0 \& M$ costs. 2 Ignoring the chemical cost component, then, a better estimate of the annual $0 \& M$ savings would be $\$ 23,250(0.93 \times 25,000)$. These savings could be passed on to homeowners in the form of lower sewer service charges.

If the treatment plant is operating considerably below capacity when residential wasteflows are reduced as a result of water-saving devices, it is difficult to determine whether sewer service charges will increase, decrease or remain constant. Where service charges are directly related to metered water use, treatment plant revenues will. decline due to water conservation efforts. If the reduction in $0 \& M$ costs is insufficient to offset this revenue decline, sewer rates may have to be increased in the short run. Conversely, if a fixed periodic sewer charge is utilized or if the $0 \& M$ cost reduction is great enough to offset the decline in revenue when service charges depend on water use, then charges may remain the same or even decline.

In addition to annual $0 \& M$ cost savings, savings in new plant construction costs can be achieved by utilities in growing communities where capacity expansions are being planned. In these communities, a reduced demand for wastewater treatment can lower the new capacity requirements and thus the cost of new plant construction. Reduced demand could result from a requirement that new homes be equipped with water-saving devices.

Table 3.7 presents estimates of construction costs for new non-lagoon secondary treatment plants by wastewater flow rate. For example, the construction cost for a plant with a capacity of $2.5 \mathrm{mgd}$ is $\$ 5.2 \mathrm{million}$. Assuming that 50 gpcd of wastewater are generated, this plant can serve the household needs of a community with 50,000 new residents. By comparison, a requirement that new homes be equipped with water-saving devices might reduce the wastewater flowing

1 This savings figure assumes that personnel adjustments can be made. Personnel costs represent 55 percent of annual O\&M costs (see U.S. Environmental Protection Agency, Determining Wastewater Treatment Costs for Your Community, p. 15).

2 Ibid. 
Table 3.6 Annual O\&M Costs for Non-Lagoon Secondary Treatment Plants, by Flow Rate

\begin{tabular}{cc}
$\begin{array}{c}\text { Flow Rate } \\
\text { (mgd) }\end{array}$ & $\begin{array}{c}\text { O\&M Costs } \\
0.5\end{array}$ \\
\hline 1.0 & 105 \\
1.5 & 130 \\
2.0 & 155 \\
2.5 & 180 \\
3.0 & 205 \\
3.5 & 230 \\
4.0 & 255 \\
4.5 & 280 \\
5.0 & 305 \\
\hline
\end{tabular}

Source: U.S. Environmental Protection Agency, Determining Wastewater Treatment Costs for Your Community, $p \cdot 13$. Costs are in January 1979 dollars. 
Table 3.7 Cost of New Non-Lagoon Secondary Treatment Plant Construction, by Flow Rate

\begin{tabular}{cc}
$\begin{array}{c}\text { Flow Rate } \\
\text { (mgd) }\end{array}$ & $\begin{array}{c}\text { Construction Cost } \\
\text { (mililon dollars) }\end{array}$ \\
\hline 0.5 & 1.6 \\
1.0 & 2.7 \\
1.5 & 3.6 \\
2.0 & 4.4 \\
2.5 & 5.2 \\
3.0 & 5.9 \\
3.5 & 6.6 \\
4.0 & 7.2 \\
4.5 & 7.9 \\
5.0 & 8.5
\end{tabular}

Source: U.S. Environmental Protection Agency, Construction Costs for Municipal Wastewater Treatment Plants: 1973-1978. EPA/430/9-80-003. Washington, DC, April 1980, p. 91. Costs are in January 1979 dollars. 
from these homes by 20 percent (i.e., from 50 to 40 gpcd). In this case, a new plant could be built with a capacity of only $2.0 \mathrm{mgd}$, and could serve all the 50,000 new residents for a cost of only $\$ 4.4$ million, as indicated in table 3.7 . Savings in new plant construction cost due to this requirement would therefore total $\$ 800,000$.

In addition to savings in new plant construction, the smaller capacity plant yields savings to the utility in annual O\&M costs. These savings are calculated as were those above, so annual O\&M savings to the utility in this example are similarly $\$ 23,250$.

A requirement in a growing community that new homes be equipped with watersaving devices has thus yielded the utility savings in new plant and annual O\&M costs of $\$ 800,000$ and $\$ 23,250$, respectively. Such savings could be passed on to homeowners in the form of lower sewer connection and service charges. 1

It should be emphasized that the cost of wastewater treatment (and therefore the value of the overall benefit to be derived from reduced water consumption) is largely dependent on the conditions prevaling in a particular community. Labor rates, chemical costs, utility costs, construction materials costs, effluent concentration, the proportion of total waste flow attributable to residential water consumption, a particular plant's capacity to handle the wastewater generated, and the treatment process used are the main factors affecting local wastewater treatment costs and the potential overall benefits from the use of water-conserving devices.

\subsubsection{Energy Saved}

A significant benefit is to be gained in the area of energy savings through the use of water conservation devices. Energy is a factor in almost every phase of residential water use. It is consumed through the water supply processes of obtaining water, purifying it, and distributing it to points of use. Energy is also consumed in wastewater purification through various treatment processes. The most significant residential water use process in terms of its energy requirements is water heating, which accounts for over 90 percent of all residential water-related energy consumption. 2 The most effective way to reduce the amount of energy used to heat water in homes is to reduce the amount of water to be heated, through the application of water-saving devices. This is the only aspect of energy savings that will be discussed in this section. 3

1 According to U.S. Environmental Protection Agency, Determining Wastewater Treatment Costs for Your Community, po 8, the Federal Government will pay 75 percent ( 85 percent in some cases) of the costs involved in constructing, enlarging, or upgrading a treatment facility. Thus, some of the $\$ 800,000$ of new plant construction cost savings may accrue to the Federal Government.

2 Robert L. Palla, Jr., The Potential for Energy Savings with Water Conservation Devices, pp. 10-11.

3 For other ways to reduce energy consumption due to water heating, see Joseph Carter and Robert G. Flower, "The Micro-Load," Solar Age, Vol. 5, No. 9 (September 1980), pp. 22-30. 
To determine the annual dollar value of energy savings due to use of a water conservation device, it is first necessary to know the amount of water saved by the device, the temperature of the water as it enters the house (Incoming temperature), the temperature of the water as it is used by the device (service temperature), the efficiency of the water heater, and the price of the fuel being used. Table 3.8 lists three of the most common residential water heating systems by fuel type and gives their relative frequencies of occurrence, assumed combustion efficiencies, and average fuel prices. 1 The combustion efficiency of a water heater is its energy output per unit of energy input. Efficiencies vary even for water heating systems with a given fuel type. The efficiencies assumed in this subsection are listed in table 3.8. The average prices paid in the United States for each of the fuel types are taken from the October 27 , 1980 Federal Register.

The annual dollar value of energy savings brought about by a device using a given type of water heating fuel can be calculated as follows:

$$
\text { AES }=8 \times \text { DWS } \times 365 \times\left(T_{S}-T_{i}\right) \times(1 / e) \times P \times 10^{-6},
$$

where $\mathrm{AES}=$ annual value of energy savings through the use of a water-saving device $\left(\$ / y_{*}\right)$;

8 = energy output required to raise the temperature of a gallon of water $1^{\circ} \mathrm{F}\left[\mathrm{Btu} /\left(\mathrm{gal} \times{ }^{\circ} \mathrm{F}\right)\right]$;

DWS = daily water savings of the device (gpd);

365 = number of days per year;

$\mathrm{T}_{\mathbf{S}}=$ service water temperature $\left({ }^{\circ} \mathrm{F}\right)$;

$\mathrm{T}_{1}=$ incoming water temperature $\left({ }^{\circ} \mathrm{F}\right)$;

$\mathrm{e}=$ combustion efficiency of the water heater; and

$\mathrm{P}=$ price of the fuel $\left(\$ / 10^{6} \mathrm{Btu}\right)$.

Table 3.9 lists some devices, their daily water savings, and the service temperature of the water they use. Assuming the incoming temperature of the water is $55^{\circ} \mathrm{F}$ and using equation 3.1, the annual dollar value of energy savings was calculated for each fuel type for a household of four and also included in table 3.9. As an example of how these savings are calculated, assume that a flow control showerhead is installed in a house that has four occupants, one shower, and a water heater using natural gas. In this case, the following values are to be used in equation 3.1: 40 for DWS and 107 for $T_{S}$ (table 3.9); 55 for $T_{i}$ (above); and 0.70 for $e$ and 3.83 for $P$ (table 3.8). The result is an annual dollar value of energy savings of $\$ 33.23 .2$ As this example shows, homeowners can derive a substantial benefit from the energy savings assoclated with the use of water-conserving devices.

1 For the use of marginal fuel prices in valuing saved energy, see Wallace J. Hopp and William P. Darby, "Household Water Conservation: The Role of Indirect Energy Savings," Energy: The International Journal, Vol. 7, No. 3 (December 1980), p. 1185 .

2 To find the lifetime dollar value of energy savings, the annual dollar savings have to be converted to their equivalent present value, as discussed in section 5 . 
Table 3.8 Frequencies of Occurrence, Assumed Efficlencies, and Fuel Prices for Residential Gater Heating Systens, by Type of Fuel

Fuel Type

NaturaI Gas

Electricity

Fuel 011

Other

$$
\text { Rreguency of }
$$

Occurrence $(\%)^{2}$

$$
54.7
$$

32.8

7.2

5.3

100.0

\section{Assured}

Efficiency

0.70

1.00

0.67

7.21
Fuel Price $\left(\$ / 10^{6} \mathrm{Btu}\right)^{\mathrm{C}}$

3.83

27.58

a The frequencies are from the U.S. Bureaw of the Census, "1977 Annual Housing Survey," unpublished tabulation of the Departuent of Energy Supplement, Washington, DC.

b The assumed efficiencies are from Hopp and Darby, PR. $118 \%$, 1189.

C The prices are U.S. averages from the U.S. Department of Brezgy, Office of Solar Energy and Conservation, Federal Register, Fol. 45 , No. 209 (October 27, 1980), p. 71339. 


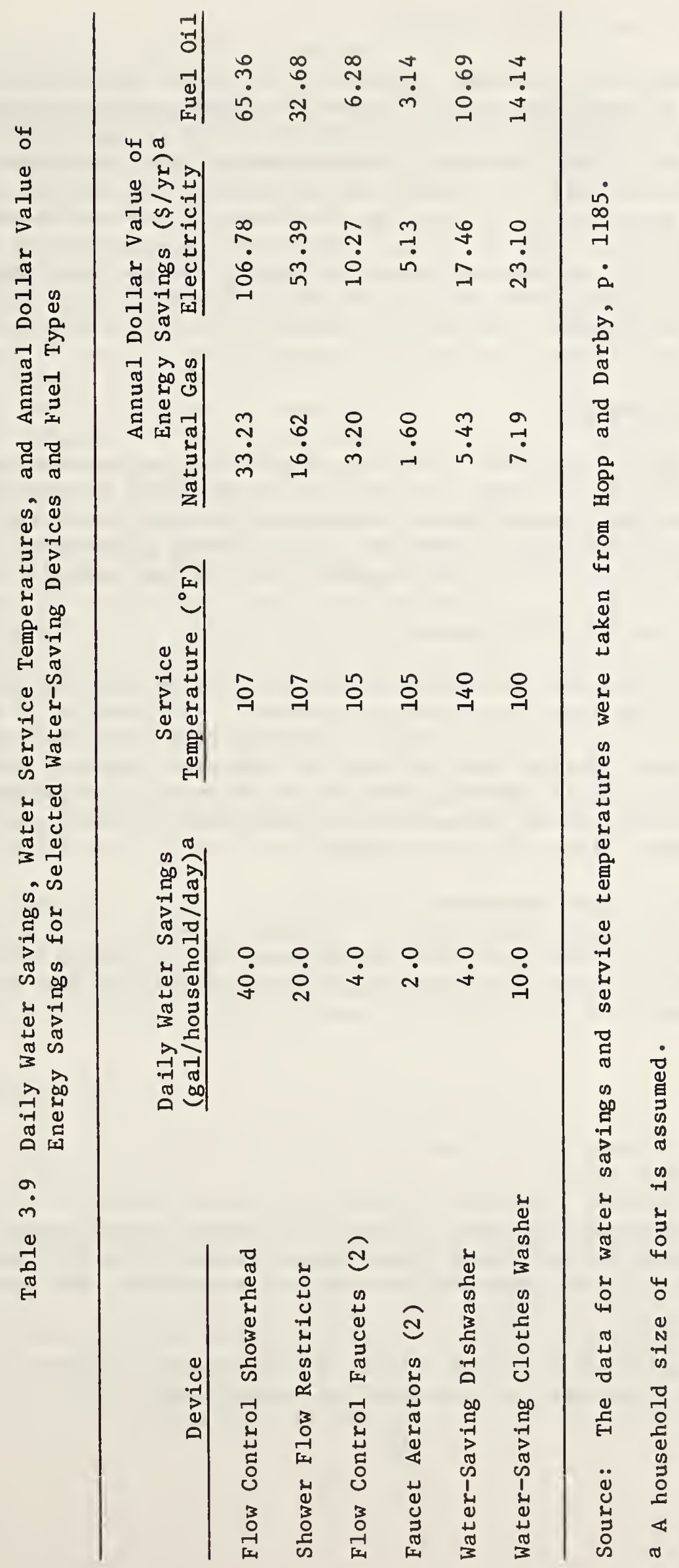




\section{AN EXAMINATION OF WATER RATE SCHEDULES}

One of the crucial factors in making cost-effective water conservation decisions is the dollar value of conserved water. Given an amount of water saved, the corresponding dollar savings reflected in the homeowner's water bill is determined by the local water rate schedule. Because water rate schedules are complex, however, the water rate most likely to be used by analysts in calculating the dollar value of water savings, that is, the average price of water, will usually be quite different from the actual price the homeowner would have to pay for the water. This section begins by explaining the various types of water rate schedules. Then it analyzes a national sample of schedules in terms of the mean values for key variables, including the actual price of conserved water and the average price of water.

\subsection{TYPES OF RATE SCHEDULES}

Water differs from most commodities in that charges for its use are based on a rate schedule rather than on a single price. A single price is the charge per unit (unit rate) applicable to all units consumed. Charges in a rate schedule, on the other hand, vary with one or both of the following parameters:

(1) amount of water consumed; and (2) length of the billing period.

\subsubsection{Fixed Charge per Period Schedule}

Under this rate schedule, all customers are charged the same dollar amount per period regardless of the quantity of water consumed. For example, a household using 5000 gallons per month and one using 10,000 gallons per month receive the same water bill. Fixed charges must be used for customers without water meters. Twenty-seven percent of the water delivered to residences by government owned utilities is not metered and 43 percent of that delivered by investor owned utilities in the United States is not metered.1

\subsubsection{Uniform Rate per Unit Schedule}

Under this rate schedule, the unit rate is the same for all units of water consumed.2 A typical uniform rate schedule might charge $\$ 1.00$ for every 1000 gallons of water used.

1 These statistics were derived from the American Water Works Association, "Statistical Summary of the United States Water Works Industry," September 1979, assuming that all of the water that is not metered is delivered to residences.

2 This is the equivalent of a single price. Uniform rates, however, are usually combined with other charges, as discussed in subsection 4.1 .5 . 


\subsubsection{Varying Rates per Unit Schedules}

Declining block rates schedule. Under this rate schedule, a certain price per unit is levied for all units consumed up to a specified quantity. Such a bounded consumption range is known as a "block" of water. For water consumed in the next block, a lower unit price is charged. In this manner unit prices decrease for succeeding blocks of water.

Increasing block rates schedule. This rate schedule is the reverse of the declining block rates type in that unit prices increase with succeeding blocks of water. An innovative type of increasing block rates schedule is composed of many blocks, each of which covers a relatively small range of consumption. The range covered by each block is expressed in terms of average daily consumption during the billing period rather than in the more common terms of total consumption during that time. Furthermore, the rate corresponding to each block is expressed as an average price (applicable to total consumption) rather than as a marginal price (applicable to consumption in that block only). Nevertheless, this schedule can be expressed as a traditional increasing block rates schedule by converting average daily consumption and average prices to total consumption and marginal prices, respectively. Table 4.1 presents an example of this type of increasing block rates schedule. According to this example, if a household were to consume 6000 gallons of water during a month, the average daily consumption would be 200 gallons, with an average price of $\$ 0.88$ per 1000 gallons. Thus, the water bill would be $\$ 5.28 .1$

\subsubsection{Peak Load Pricing Schedules}

Seasonal rates schedule. Under this rate schedule, higher unit rates are imposed in the summer, when demand increases due to lawn sprinkling. The unit rates can be either uniform or varying.

Surcharge schedule. Under this pricing scheme, uniform or varying rates are charged for a base amount of water. This base is established according to each customer's average daily consumption for winter or the entire year. Higher rates are charged for water in excess of the base. These higher rates can be applied either during the summer sprinkling season or throughout the year.

\subsubsection{Mixed Schedules}

Most rate schedules in effect today are mixed in the sense of combining unit rates with a flat charge. The flat charge can be either a minimum charge or a fixed charge. A minimum charge includes a certain allotment of water, beyond which unit rates apply. In this analysis, a minimum charge allotment is treated as a block. A fixed charge in a mixed schedule does not include a water allotment, so that the unit rates are imposed beginning with the first gallon of water consumed. Flat charges are used as a means of covering the costs of billing, metering, maintenance, and in some cases fire protection. The possible

$1(\$ 0.88 / 1000 \mathrm{gal}) \times 6000 \mathrm{gal}=\$ 5.28$. 
Table 4.1 Innovative Increasing Block Rates Schedule

Average Daily Consumption

By Household During

Month

(Gallons Per Day)

Less Than 20

20-29

$30-39$

40-49

$50-59$

$60-69$

$70-79$

$80-89$

90-99

100-109

110-119

120-129

130-139

140-149

$150-159$

160-169

$170-179$

180-189

190-199

200-209

210-219

220-229

230-239

240-249

250-259

260-269

270-279

280-289

290-299

-

-

-
Average Price

$(\$ / 1000 \mathrm{Gallons}$ of

Total Consumption)

0.54

0.55

0.56

0.57

0.58

0.59

0.60

0.61

0.63

0.66

0.68

0.70

0.72

0.74

0.76

0.78

0.80

0.82

0.85

0.88

0.89

0.90

0.92

0.93

0.95

0.97

0.99

1.00

1.02

Source: Washington Suburban Sanitary Commission, WSSC Pipeline, Hyattsville, MD, October 1978, pp. 3-4. 
combinations of flat charges and unit rates are: fixed/uniform, fixed/varying, fixed/peak load, minimum/uniform, minimum/varying, and minimum/peak load.

\subsubsection{Conservation Potential of Rate Schedule Types}

The various rate schedules described above differ in the conservation incentives they can provide. Fixed charges provide no incentive to install water-saving devices because the quantity of water used is not related to the price of water. The uniform rate schedule fosters water conservation in a manner that does not vary with increased consumption. The declining block rates schedule provides a conservation incentive that diminishes as consumption increases. On the other hand, the increasing block rates schedule and peak load pricing schedules have the most potential for inducing water conservation by creating an incentive that increases with greater water use. This type of incentive is likely to be most effective in reducing the lawn sprinkling component of water use. In regard to the various mixed schedules, the incentive to conserve depends on the type of unit rate in the schedule. One exception occurs when consumption lies within the minimum charge block. Regardless of the type of unit rate that follows, this mixed schedule provides no incentive to conserve because the homeowner must still pay the full minimum charge.

\subsection{ANALYSIS OF A NATIONAL SAMPLE OF RATE SCHEDULES}

In this subsection a national sample of 90 water rate schedules is analyzed in terms of the mean values for key schedule variables, including the actual price of conserved water and the average price of water. The sample was drawn from a survey by the American Water Works Association (AWWA) of its entire utility membership. Over 700 rate schedules from 1978 and early 1979 were submitted.1

\subsubsection{Sample Selection}

The sample of 90 schedules resulted from an attempt to select at random from the 700 submitted schedules 2 for each State (and the District of Columbia). If a rate schedule was ambiguous, it was eliminated from the sample and another was selected at random for that State. The AWWA survey yielded 0 schedules for two States and only 1 schedule for eight states.

Table 4.2 presents the relative frequency of schedule types for the sample of 90 water rate schedules. ${ }^{2}$ The results are similar to those reported in a

1 These rate schedules were kindly provided to the National Bureau of Standards by George L. Craft, Resources Engineer, Technical Services Department, AWWA, Denver, Co.

2 Schedule types were determined based on charges for the first 50,000 gallons of consumption per month. This limit represents "maximum" residential water consumption per month - the average monthly consumption for a household of six in Alaska, the State with the highest per capita consumption level. 
Table 4.2 Relative Frequency of Water Rate Schedule Types for a Sample of 90 Schedules $^{a}$

Type of Rate Schedule

Uniform Rate

Fixed Charge/Uniform Rate

Fixed Charge/Declining Rates

Fixed Charge/Increasing Rates

Fixed Charge/Seasonal Rates

Minimum Charge/Uniform Rate

Minimum Charge/Declining Rates

Minimum Charge/Increasing Rates

Total
Relative

Frequency (\%)

2.2

6.7

4.4

3.3

1.1

25.6

55.6

1.1

100.0

a Rate schedules were categorized on the basis of charges for the first 50,000 gallons of consumption per month. 
study restricted to the State of Minnesota.1 Note that over half the utilities use the minimum charge/declining rates type of schedule and another 25 percent the minimum charge/uniform rate type. Furthermore, less than 6 percent of the rate schedules are types that provide a conservation incentive that increases with more water use (fixed/increasing, fixed/seasonal, and minimum/increasing). This suggests that the redesign of rate schedules could lead to increased water conservation.

To assure comparability of rate schedules within the sample, a number of guidelines were followed:

1. Schedules were converted to an equivalent monthly basis. For example, the flat charges and block ranges of quarterly schedules were divided by three.

2. If single- and multi-family dwellings were subject to different schedules, the single-family schedule was used. Similarly, residential schedules were used wherever commercial, industrial, and residential uses were subject to different schedules.

3. If customers with different meter sizes were subject to different schedules, the schedule for a $3 / 4$ inch meter was taken. If a $3 / 4$ inch meter was not specified, then the schedule for the next smaller meter size was used. In general, higher flat charges were levied for larger meter sizes.

4. When different schedules applied to customers inside and those outside a particular city, the schedule for customers inside the city was used. Similarly, when a special section of the area serviced was subject to a different schedule, that schedule was not used. For example, schedules were not used for those areas where booster pumping was required.

5. Some schedules had separate charges for sewer treatment. For consistency, these charges were excluded. If the charges were not explicitly included in the schedule, it was assumed that the cost of sewer service was not covered by the schedule.

6. Charges for fire protection were not included.

7. If a seasonal rate schedule prevailed, an average of the winter and summer rates was used.

1 Richard L. Gardner, An Analysis of Residential Water Demand and Water Rates in Minnesota, $\mathrm{PB}-291687$, prepared by the University of Minnesota for the Office of Water Research and Technology, Washington, DC, September 1977 , p. 31. The only marked differences are Gardner's relative frequency for the minimum charge/uniform rate schedule type of less than 3 percent, which is compensated for by his relative frequency for the fixed charge per period schedule type of 23 percent. 
8. If utility taxes were specified, they were added to the rates accordingly.

Two measures were needed to determine that portion of each rate schedule relevant to this analysis: (1) typical per capita residential water consumption; and (2) the range of household sizes that accounts for most single-family dwelling units. First, figures for typical per capita residential water consumption were obtained in terms of both a national average and averages for each State. Consequently, the rate schedules were analyzed two ways: (1) using a fixed consumption level, and (2) using consumption levels that varied from State to State. In general, the results from the use of a fixed consumption level were similar to those from the use of varying levels. Therefore, the results presented in the next subsection are those based on the use of a fixed consumption level, namely, 54.6 gallons per capita per day (gpcd).1 Secondly, it was found that families of from two to six people comprise over 92 percent of all people in families living together in a household.2 Consequently, rate schedules were analyzed using these five household sizes.

\subsubsection{Mean Values of Rate Schedule Variables}

A computer program generated the mean values of key rate schedule variables for the sample. These values are presented in table 4.3 for households of from two to six people with consumption levels based on the national average for per capita residential water consumption. The total charges on a monthly water bill range between $\$ 5.02$ for a household of two and $\$ 9.98$ for a household of six (column 3). Assuming these average values in column 3 approximate a typical schedule, they can be used to get an idea of the order of magnitude of savings that might be achieved. For example, if consumption for a household of six is reduced by one-half (from $9828 \mathrm{gallons} / \mathrm{month}$ to $4914 \mathrm{gallons} / \mathrm{month}$, column 2 ), the monthly bill is reduced by $\$ 3.81$ ( $\$ 9.98-\$ 6.17$, column 3 ).

1 Average State and national consumption levels were derived from data on all water withdrawn for public supplies; losses and public uses; domestic use, losses, and public uses; and population served, published in C. Richard Murray and E. Bodette Reeves, Estimated Use of Water in the United States in 1975, Geological Survey Circular 765, Arlington, VA, 1977, pp. 4 and 20-21. The national average used here, $54.6 \mathrm{gpcd}$, lies within the 50 to $60 \mathrm{gpcd}$ range suggested as a rule of thumb by the AWWA.

2 A figure for people in families living together was used as opposed to one for people in all household types, based on the assumption that families living together are more representative of the single-family housing population than are all households. Incidentally, households of all types (including but not restricted to families living together) with from two to six people comprise 85 percent of the total household population. U.S. Bureau of the Census, Statistical Abstract of the United States: 1979, 100th edition, Washington, DC, 1979, pp. 4, 46, 49. 


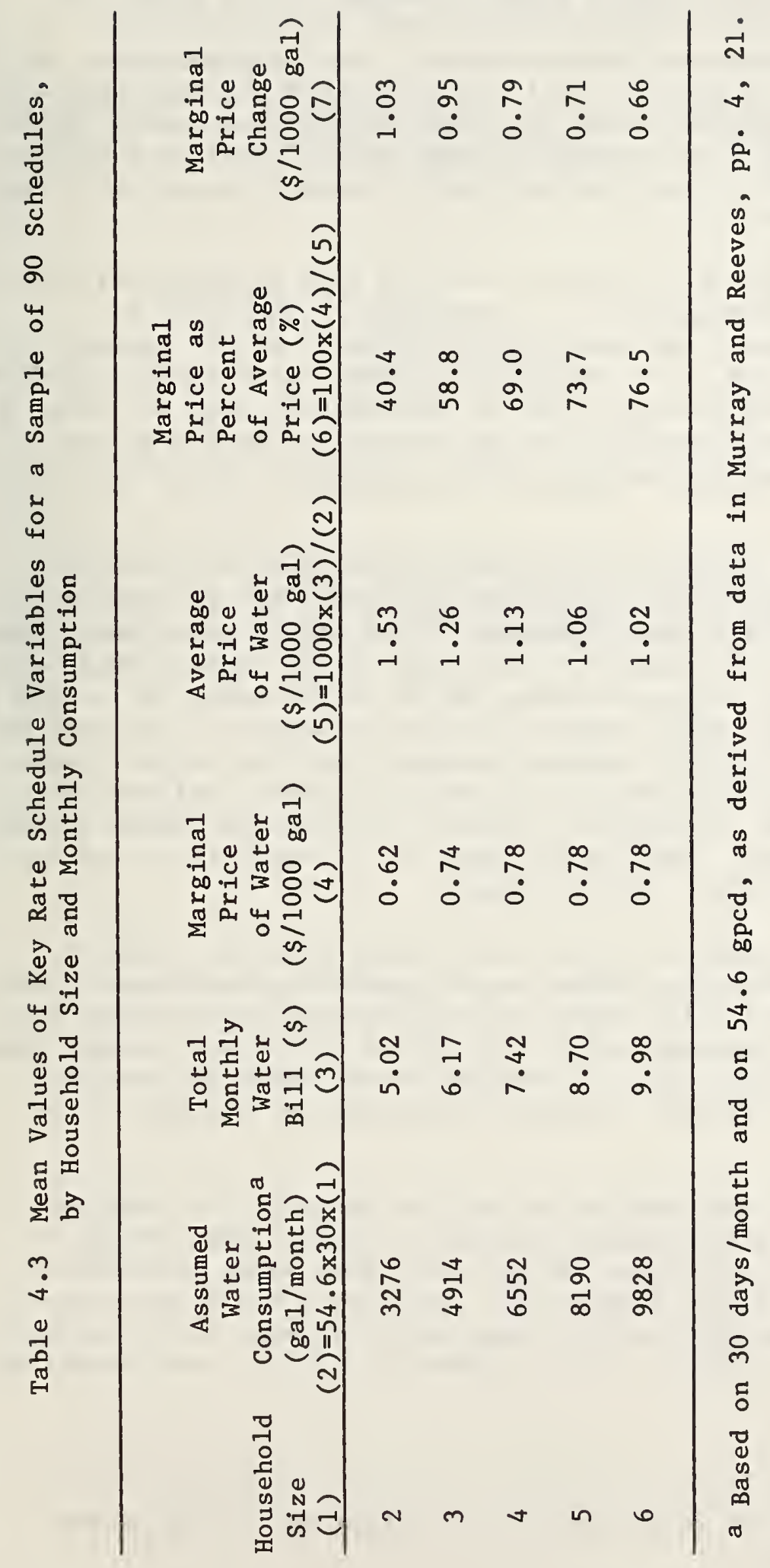


The value a homeowner receives from reducing water consumption is reflected in lower water bills. Each unit of water saved is valued at the price the homeowner would have to pay for the water, as specified by the local rate schedule. This price is the marginal price of water. The marginal price of water is the increase in the total water bill resulting from the last unit of water consumed. The unit price associated with each non-minimum charge block is the marginal price for each unit consumed in that block. A minimum charge block implies a marginal price of zero for each unit consumed within the range covered by its water allotment.

The results in column 4 of table 4.3 indicate that the mean marginal price for the block of water in which consumption for a household of four lies is $\$ 0.78 / 1000$ gallons. In contrast, the mean average price of water ${ }^{1}$ (column 5 ) is as much as $\$ 1.13 / 1000$ gallons for a household of four. This striking difference between marginal price and average price is more clearly seen in column 6 of table 4.3, which presents the ratio of the two prices for each household size. For a household of four, the marginal price represents only 69 percent of the average price.

The primary reason for such a sizeable difference between marginal price and average price is the widespread use of large flat charges. As observed in table 4.2 , over 97 percent of the rate schedules in the sample have these fixed or minimum charges. Moreover, as table 4.4 indicates, these charges which are unrelated to consumption are a large percentage of the total water bill. For a household of four, for example, flat charges comprise on average 55 percent of the total water bill. These charges increase average price and in most cases leave marginal price unaffected. Where the allotment of water included with a minimum charge is greater than consumption, however, the minimum charge serves to lower marginal price to zero. This is the case for a household of two in over one-third of the rate schedules in the sample.

The marked difference between marginal price and average price may lead to unsound decisions. When determining whether water-conserving devices will pay for themselves, estimated water bill reductions will frequently be overstated if calculated on the basis of average price. The fixed or minimum charge, which tends to raise average price, must be paid whether or not water is conserved. The accurate indicator of a homeowner's benefit from reducing consumption is marginal price.

Column 7 of table 4.3 presents the sample mean of the variable that indicates the magnitude of the marginal price change expected to result when moving to the next lower block in a rate schedule, as may occur when water consumption is reduced. Those schedules for which consumption lies within the range covered by the first block are not included in this calculation because it is impossible to move to a lower consumption block. For a household of four, such schedules

1 The average price of water (in $\$ / 1000$ gallons) is given by: (1000 $x$ total water bill)/gallons consumed. 
Table 4.4 Charges Unrelated to Consumption as a Percentage of Total Water Bill, by Household Size and Monthly Consumption

\begin{tabular}{|c|c|c|}
\hline $\begin{array}{l}\text { Household } \\
\text { Size } \\
\text { (1) }\end{array}$ & $\begin{array}{c}\text { Assumed Water } \\
\text { Consumption }(\text { gal/month })^{a} \\
(2)=54.6 \times 30 \times(1)\end{array}$ & $\begin{array}{c}\text { Charges Unrelated to Consumption } \\
\text { Percentage of Water Bill }(\%) \\
\text { (3) }\end{array}$ \\
\hline 2 & 3276 & 81.4 \\
\hline 3 & 4914 & 66.2 \\
\hline 4 & 6552 & 55.0 \\
\hline 5 & 8190 & 46.9 \\
\hline 6 & 9828 & 40.9 \\
\hline
\end{tabular}

a Based on 30 days/month and on $54.6 \mathrm{gpcd}$, derived from data in Murray and Reeves, pp . 4, 21 .

b Calculated by totaling all fixed and minimum charges and dividing the result by the sum of all total water bills for each household size. 
amount to 23 percent of the total. As column 7 shows, the mean marginal price change is $\$ 0.79 / 1000$ gallons for a household of four. This large change in marginal price can be explained by the prevalence of rate schedules with just two blocks applicable to the homeowner, one of which covers the allotment included with a minimum charge. For these schedules, since a minimum charge allotment implies a first block with a marginal price of zero, the change in marginal price from the second block to the first is the full marginal price corresponding to the second block. Of those schedules included in the mean marginal price change calculation for a household of four, 81 percent have two blocks, one of which covers a minimum charge allotment. Therefore, for this 81 percent, a move from the second block to the first results in a fall in marginal price as large as the marginal price corresponding to the second block.

A large change in marginal price emphasizes the importance of choosing the correct block when valuing each unit of water saved. The block determines the marginal price, which measures the true value of conserved water.

\subsubsection{Lawn Sprinkling}

Water consumption increases significantly in the summer due to lawn sprinkling. The sprinkling component of water use has been reported to constitute from as little as 3 percent ${ }^{1}$ to as much as 70 percent $^{2}$ of residential consumption.

Some utilities use peak load pricing schedules to adjust for the additional system capacity required in the summer due to sprinkling. Some charge seasonal rates, that is, higher rates in the summer. Others levy higher rates for "excess" water consumed. And at least one utility compensates by charging higher rates year round to customers with larger lawns. In the sample of 90 schedules analyzed, only one utility used a peak load pricing schedule.

Even if a homeowner does not face a peak load pricing schedule, the value of water saved in the summer and winter can be substantially different because it depends on the level of consumption prior to conservation. To get an idea of just how different the dollar savings can be, the sample means in column 3 of table 4.3 can be assumed to approximate a typical schedule and then compared across household sizes. For example, if it were summer and one consumed 8190 gallons per month before conservation and 6552 gallons per month after conservation (column 2 ), one would save $\$ 1.28$ on the monthly water bill ( $\$ 8.70-\$ 7.42$, column 3). On the other hand, if it were winter and one consumed 4914 gallons per month before and 3276 gallons per month after conservation (saving the same amount of water as in the summer), one would save only $\$ 1.15$ on the monthly water bill ( $\$ 6.17-\$ 5.02)$. Thus, for the same amount of water savings, water bill reductions can differ by season because of lawn sprinkling.

1 Bailey, et al., p. 5 .

2 Donald J. Cotter and Don B. Croft, Water Application Practices and Landscape Attributes Associated with Residential Water Consumption, Report No. 49, Las Cruces, NM: New Mexico Water Resources Research Institute, November 1974 , p. 4. 


\subsubsection{Conclusions}

The foregoing analysis of a national sample of water rate schedules emphasizes that the marginal price of water, rather than its average price, measures the true dollar value to homeowners of conserved water. Generally, the marginal price associated with each unit of water saved is considerably lower than the average price paid for water. Thus, estimated water bill reductions will frequently be overstated if calculated on the basis of average price.

A similar study could be undertaken for sewer and energy rate schedules. Because some wastewater treatment and water heating are avoided as a result of water conservation, a study of sewer and energy rate schedules would contribute to more rational water conservation decisions. 
Given the wide variety of water-saving devices discussed in sections 2 and 3 , a rational method is needed to select devices for new and retrofit applications. This section presents a comprehensive method for making both of these decisions based on economic efficiency criteria. The method presented addresses two basic situations: ( 1 ) evaluation of several devices all of which serve the same plumbing function so that only one can be utilized with regard to a given fixture (mutually exclusive devices); and (2) evaluation of devices each of which serves a different function so that all of them could be used simultaneously by one household (compatible devices). Each situation and its appropriate decision rule will be discussed in turn.

\subsection{MUTUALLY EXCLUSIVE DEVICES}

To illustrate the concept of mutually exclusive water-saving devices, consider three alternative shower modifications: (1) replacement with a new low-flow showerhead (3 gpm); (2) replacement with a new medium-flow showerhead ( $4 \mathrm{gpm}$ ); or (3) adding a flow restrictor upstream of the existing showerhead. These alternatives are mutually exclusive in that only one of them could be applied to any particular shower. The homeowner needs to know whether any of the three alternative modifications represents an economic improvement over the existing shower and, if so, which one represents the greatest economic improvement. Both these decisions can be made by applying a single economic evaluation measure: Net Present Value.

The Net Present Value (NPV) measure is calculated for each alternative water-saving device in the following manner:

$$
\mathrm{NPV}=[\mathrm{W}+\mathrm{En}]-[\mathrm{Ac}+\mathrm{I}+\mathrm{M}+\mathrm{R}],
$$

where NPV = Present value of the net benefits expected to result from installing a particular alternative device;

$W=$ Present value of water and wastewater treatment savings, calculated by evaluating the annual amount of water expected to be saved at the marginal price(s) for each unit of water saved (including per unit sewer charges and taxes) and discounting to the present;

En = Present value of energy savings from reduced hot water usage, calculated by evaluating the annual amount of energy expected to be saved at the marginal price(s) for each energy unit saved (including taxes) and discounting to the present;

$A c=$ Acquisition cost of the retrofit device for an existing fixture or the differential acquisition cost of a newly installed water-saving fixture compared with a standard model;

I = Installation cost of the retrofit device or the differential installation cost of a newly installed water-saving fixture compared with a standard model; 
$M=$ Present value of operation, maintenance, and repair costs expected to result from the retrofit device or from the special feature of a newly installed fixture; and

$R=$ Present value of the cost of replacing the retrofit device or the special feature if replacement is expected during the homeowner's planning horizon.

Note that the shower illustration described above concerns the modification of an existing plumbing fixture (retrofit application). The same NPV measure can be calculated for a special water-saving feature that is part of a new fixture being installed in a new application, that is, when building a new home, when renovating or adding to an existing home, or when replacing an entire fixture for reasons other than water conservation (e.g., malfunction, or change of decor or style). When evaluating water-saving features of new fixtures, however, one must be careful to include as acquisition, installation, operation, maintenance, and repair cost components ( $A C, I$, and $M$ ) only the differential costs of these new fixtures. The differential cost estimates are derived by subtracting the costs of a comparable conventional fixture from those of the fixture being evaluated. If replacement of the water-saving feature or of the entire fixture is anticipated during the planning horizon, then the cost of re-introducing that feature into the existing or the replacement fixture should be taken into account.

The discounting of future values (savings or costs) to the present in equation (5.1) is accomplished by applying the standard discount formulas presented in table 5.1. For example, if a low-flow showerhead that costs $\$ 10$ at today's prices is expected to need replacement at the end of year 15 , and the real rate of interest ${ }^{1}$ is 8 percent, then one would discount the replacement cost as follows:

$$
\begin{aligned}
\mathrm{PV} & =\mathrm{F} \cdot(1+\mathrm{i})^{-\mathrm{n}} \\
& =\$ 10.00 \cdot(1.08)^{-15} \\
& =\$ 10.00 \cdot(0.3152)=\$ 3.15 .
\end{aligned}
$$

Similarly, if the annual dollar value of the water and wastewater treatment savings from the low-flow showerhead is expected to be $\$ 20$, the planning horizon of the homeowner is 20 years, and the real interest rate is 8 percent, then the discounting would be carried out as follows:

$$
\begin{aligned}
\mathrm{PV} & =A \cdot\left[\frac{1-(1+i)^{-n}}{i}\right] \\
& =\$ 20.00 \cdot\left[\frac{1-(1.08)^{-20}}{.08}\right]
\end{aligned}
$$

1 The real rate of interest excludes inflation. 
Value being Discounted

Single Future Value (F)

Uniform Recurring Value (A)

Escalating Recurring Value (E)*
Formula for Present Value (PV)

$\mathrm{PV}=\mathrm{F} \cdot(1+\mathrm{i})^{-\mathrm{n}}$

$\mathrm{PV}=\mathrm{A} \cdot\left[\frac{1-(1+i)^{-n}}{i}\right]$

$\mathrm{PV}=\mathrm{E} \cdot\left[\frac{1+\mathrm{e}}{1-\mathrm{e}}\right] \cdot\left[1-\left(\frac{1+\mathrm{e}}{1+\mathrm{i}}\right)^{\mathrm{n}}\right]$

where

$F$ = future value occurring once at the end of period $n$;

$A=$ constant value repeated regularly at the end of each of $n$ periods;

$E$ = escalating value increasing at a constant growth rate, e, and repeated regularly at the end of each of $n$ periods;

$i=$ real (excluding inflation) rate of interest per period;

$\mathrm{n}=$ number of compounding periods; and

$e=$ real (excluding inflation) rate of growth per period of an escalating value (e.g・, the price of energy).

Assumes $i \neq e$. For the special case of $i=e, P V=E \cdot n$. 


$$
=\$ 20.00 \cdot(9.818)=\$ 196.36 \text {. }
$$

The last formula in table 5.1 is employed when a recurring value, rather than remaining fixed over the planning horizon, is expected to increase at a constant rate greater than that of general inflation. This might be likely in the case of the annual dollar value of the energy savings from reduced hot water usage. Although the same number of energy units might be saved from year to year, the dollar value of those savings could grow because of escalation in the price of energy. For example, suppose the dollar value of the annual energy savings of the showerhead is $\$ 30$ at the current price of energy. If the price of energy is expected to increase at a real (i.e., above general inflation) annual rate of 5 percent, then the present value of the energy savings over the 20 year planning horizon would be calculated, discounting at 8 percent interest, as follows:

$$
\begin{aligned}
\mathrm{PV} & =\mathrm{E} \cdot\left[\frac{1+\mathrm{e}}{i-\mathrm{e}}\right] \cdot\left[1-\left(\frac{1+\mathrm{e}}{1+\mathrm{i}}\right)^{\mathrm{n}}\right] \\
& =\$ 30.00 \cdot\left[\frac{1.05}{.08-.05}\right] \cdot\left[1-\left(\frac{1.05}{1.08}\right)^{20}\right] \\
& =\$ 30.00 \cdot(15.076)=\$ 452.28 .
\end{aligned}
$$

Before applying these discounting procedures, the analyst should eliminate from further consideration those alternatives whose acquisition and installation costs exceed the homeowner's financial budget. Then the NPV should be calculated for each affordable alternative by means of equation (5.1). The economic decision rule for choosing among these mutually exclusive alternatives is to maximize the NPV. This means selecting the affordable alternative with the highest positive NPV. If none of the alternatives yields a positive NPV, then none should be selected and the existing fixture should not be modified or the special water-saving feature should not be introduced (unless, of course, alternative water-saving modifications to or features of the fixture are available that were not evaluated).

This decision rule for selecting one (or none) among several mutually exclusive devices is illustrated in the following example. Suppose the NPVs for the three alternative shower modifications were as follows: low-flow showerhead $(\mathrm{NPV}=\$ 600)$; medium-flow showerhead $(\mathrm{NPV}=\$ 450)$; and flow restrictor ( $\mathrm{NPV}=$ $\$ 350)$. In this case, the decision rule of maximizing NPV would lead one to select the low-flow showerhead as the best alternative among the three being considered. One should note that all three modifications would represent a positive economic improvement over the existing shower, but the purpose of this decision rule is to chose the best affordable alternative given that only one can be selected (i.e., mutually exclusive alternatives).

\subsection{COMPATIBLE DEVICES}

In contrast to the shower illustration discussed above, many conservation decisions involve water-saving devices that are not mutually exclusive. These devices can be described as compatible in that it is technically feasible 
to install any combination of them in a given house. Typically, compatible devices are those which are installed or incorporated as features in different plumbing fixtures. For example, the following devices could be considered compatible with one another: low-flow showerhead, shallow trap toilet, and kitchen sink faucet flow restrictor. When evaluating these compatible devices, the analyst can select one, all, or any combination of them. The puxpose of this economic evaluation is to determine which of all possible combinations leads to the greatest net economic benefit to the homeowner. How one finds this economically optimal combination of devices depends on whether the homeowner's budget for water conservation investments is constrained or not. An unconstrained investment budget means that the homeowner would be able to finance (either through borrowing or savings) the initial, that is, acquisition and installation costs of all those devices which are shown by the evaluation to be cost-effective. An investment budget is constrained if the homeowner cannot finance all the cost-effective devices. The decision rule to follow when evaluating compatible devices under an unconstrained investment budget is similar to that for mutually exclusive devices in that it is also based on the NPV measure. The only difference arises because more than one of the compatible devices can be selected. Thus, rather than selecting the one alternative with the highest NPV, the analyst should select all of the compatible devices for which the NPV is positive and reject all the others. Clearly, the combination of devices selected on this basis yields the greatest net economic benefit to the homeowner compared with any other possible combination of the compatible devices being evaluated.

If the homeowner's investment budget is constrained, then by definition, not all devices with positive NPV can be selected. A method is needed to select the economically optimal combination of devices from among those with positive NPV. Economically optimal in this sense means the combination with the greater overal1 NPV. Before suggesting a proper method, note that the reason some positive NPV devices have to be rejected is that there are insufficient investment funds to cover the initial costs of the devices. Because investment funds are the constraining factor, each device should be evaluated in terms of its contribution to positive benefits per dollar of investment funds required to cover initial costs. That is, in order to derive the greatest economic benefit from a limited pool of water conservation investment funds, those devices with the highest benefits per investment dollar should be given priority. The algebraic form of this decision rule for selecting the economically optimal combination of compatible devices with a limited budget can now be formulated. Using the same symbols and definitions as in equation (5.1), one forms the Savings-toInvestment Ratio (SIR) for each compatible device as follows:

$$
\operatorname{SIR}=\frac{W+E n-M-R}{A C+I}
$$

The devices are then ranked by their SIR values, from highest to lowest value. All devices whose SIR is less than or equal to one should be rejected. These devices are the same as those whose NPV values are not positive. Then one should proceed down the ranked list of devices, accepting each device in sequence until the limit of the initial costs investment budget is reached. The devices included in the selection constitute that combination of water 
conservation investments which yields the greatest possible net economic gain, given the particular investment budget constraint to which the homeowner is subject.

In evaluating a11 of the water conservation options that may be appropriate for a particular residence, both of the two decision rules presented above are utilized if investment funds are constrained. That is, first the NPV measure defined in equation (5.1) is calculated for each group of mutually exclusive devices to determine the economically optimal one for each group. These optimal devices which are compatible with each other are then evaluated and ranked in terms of their SIR values, defined in equation (5.2). If the imposition of the budget constraint leads to rejection of any devices that have mutually exclusive alternatives, then SIR values should be calculated for those alternatives to see whether any of them would rank high enough to be included in the budget. 


\section{SUMMARY AND SUGGESTIONS FOR RESEARCH}

\subsection{SUMMARY}

The objective of this report has been to present a framework for utilities to use in recommending cost-effective residential water-saving devices. The most common water-saving devices were described, and published estimates of their expected water savings were provided. The principal components of costs and benefits arising from the devices were itemized, the order of their magnitude was suggested, and the proper approaches to estimating these components for economic evaluations of devices were provided. The cost components are acquisition; installation; operation, maintenance, and repair; and replacement. The benefit components correspond to the water, wastewater treatment, and energy saved by reducing water consumption.

Particular attention was given to the benefit homeowners are likely to receive in the form of reduced water bills. A detailed analysis was conducted of the types of rate schedules used by water utilities to cover their costs. A large sample of current rate schedules was studied and mean values for key variables were calculated. For household sizes of from two to six, sample means were calculated for the total monthly bill, the average price per unit of water used, and the marginal price at current consumption levels. A major finding was that, because of the prevalence of fixed and minimum charges, the marginal price paid by the homeowner, which measures the actual benefit from conservation, is significantly below the average price. For a two-person household, the marginal price is only 40 percent of the average price over the entire water bill. Thus, homeowners " conservation benefits, in terms of savings on water bills, are much less than what the average price paid for water would suggest.

The decision rules presented in section 5 will lead to recommendations of the economically optimal water-saving devices under a wide range of circumstances. When deciding which among several mutually exclusive devices should be installed, the one with the greatest positive NPV measure should be selected. When selecting a combination of compatible devices, all devices with positive NPV measures should be included, unless the investment budget is constrained. If investment funds are constrained, then the compatible devices should be ranked according to their SIR measures and the higher-ranked devices should be selected until the budget is exhausted.

\subsection{SUGGESTIONS FOR RESEARCH}

Further research is needed in a number of areas to assist utilities in recommending cost-effective water-saving devices. Field tests of the many available devices are needed to provide more accurate estimates of water savings. This research involves not only tests on flow rates but data on the frequency and duration of households' utilization of these devices. More accurate and detailed data are also needed on the useful lives and on the cost components of the devices, especially maintenance and repair costs. 
The analysis of the types of water rate schedules and the important distinction between average and marginal prices should be extended to sewer and energy utility rate schedules. In this way, each of the benefits from saving water can be accurately taken into account when making water conservation decisions.

As the economic decision framework makes clear, the cost effectiveness of watersaving devices depends on regional, local, and even house-specific factors. The costs of materials and labor used to install and maintain the devices vary with local and regional economic conditions. On the benefit side, the water savings (and wastewater treatment and energy savings as well) depend on the water supply pressure and household size of each residence, and the energy savings are a function of the incoming water temperature in the area. In addition, the local rate schedules for water, wastewater treatment, and energy crucially affect the benefits homeowners receive from reducing water consumption.

Because the cost effectiveness of water-saving devices depends critically on so many local factors, a computer program based on the economic decision framework is needed to carry out the many calculations required to analyze devices for each locality and household size. Such a flexible program could be used by water utilities to develop lists of locally recommended devices. The selection of devices would be sensitive to the actual impact that each device would have on homeowners' monthly water, sewer, and energy bills. The utility could send these lists of recommended water-saving devices directly to homeowners along with their bills. Homeowners could also be provided with actual estimates of the savings on water, sewer, and energy bills that would result from the installation of each device as well as the time it would take for the device to pay for itself through these savings. The lists developed would be sensitive to household size, number and type of plumbing fixtures, and whether the installation would be a retrofit or a new application.

Because the economic framework and proposed computer program are readily adaptable to any water utility rate schedule, it would be possible for water resource planners to estimate the effect of alternative rate schedules on residential water use. In this way, greater incentives for water conservation could be built into rate schedules. 


\section{REFERENCES}

1. American Water Works Association, "Statistical Summary of the United States Water Works Industry," September 1979.

2. Bailey, James R., et al., A Study of Flow Reduction and Treatment of Wastewater from Households. Prepared by General Dynamics for the Federal Water Quality Administration, Washington, DC, December 1969 .

3. Baker, Larry K., Bailey, Harold E. and Sierka, Raymond S., "Household Water Conservation Effects on Water, Energy and Wastewater Management," Proceedings of the Conference on Water Conservation and Sewage Flow Reduction with Water Saving Devices, Pennsylvania State University, University Park, PA, April 8-10, 1975.

4. Bishop, J.W., "Field Experiences in Water Savings Programs of the Washington Suburban Sanitary Commission," Proceedings of the Conference on Water Conservation and Sewage Flow Reduction with Water Saving Devices, Pennsylvania State University, University Park, PA, April 8-10, 1975.

5. California Department of Water Resources, Water Conservation in California, Bulletin No. 198. Sacramento, CA, May $197 \overline{6 .}$

6. Carter, Joe and Flower, Robert G., "The Micro-Load," Solar Age, Vo1. 5, No. 9 (September 1980), pp. 22-30.

7. Clark, Robert M. and Goddard, Haynes C., Pricing for Water Supply: Its Impact on Systems Management, PB-231 073. Cincinnati, OH: National Environmental Research Center, April 1974.

8. Cohen, Sheldon and Wallman, Harold, Demonstration of Waste Flow Reduction from Households, EPA-670/2-74-071. September 1974 .

9. Cotter, Donald J. and Croft, Don B., Water Application Practices and Landscape Attributes Associated with Residential Water Consumption, Report No. 49. Las Cruces, NM: New Mexico Water Resources Research Institute, November 1974.

10. Crisp, J. and Sobolev, A., "An Investigtion of the Performance of Lavatories Using Spray Taps and of Sanitary Accommodation in an Office Building," Journal of the Institution of Water Engineers, Vol. 13 (1959).

11. Feldman, S.L., A Handbook of Water Conservation Devices, NSF/RANN Grant No. APR 76-19369. Clark University, November 1977.

12. Flack, J. Ernest, Weakley, Wade P. and Hil1, Duane W., Achieving Urban Water Conservation: A Handbook, PB-278 174. Prepared by Colorado State University for the Office of Water Research and Technology, Washington, DC, September 1977. 
13. Fowell, A.J. et al., "Water and Water-Related Conservation in Buildings,"

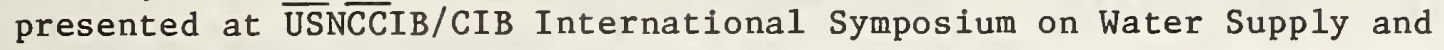
Drainage, National Academy of Sciences, Washington, DC, September 28-30, 1976.

14. Gardner, Richard L., An Analysis of Residential Water Demand and Water Rates in Minnesota, PB-291 687. Prepared by the University of Minnesota for the Office of Water Research and Technology, Washington, DC, September 1977.

15. Gysi, Marshal1, "The Effect of Price on Long-Run Water Supply Benefits and Costs," Water Resources Bulletin, Vol. 7, No. 3 (June 1971), pp. 521-528.

16. Hopp, Wallace J. and Darby, William P., "Household Water Conservation: The Role of Indirect Energy Savings," Energy: The International Journal, Vo1. 7, No. 3 (December 1980).

17. Milne, Murray, Residential Water Conservation, California Water Resources Center Report No. 35. University of California at Davis, March 1976.

18. Murray, C. Richard and Reeves, E. Bodette, Estimated Use of Water in the United States in 1975, Geological Survey Circular No. 765. Arlington, VA: Department of the Interior, 1977.

19. North Marin County (California) Water District, North Marin's Little Compendium of Water Saving Ideas, North Marin, CA, August 1976.

20. Palla, Robert L., Jr., The Potential for Energy Savings with Water Conservation Devices, National Bureau of Standards Interagency Report 79-1770. Washington, DC, September 1979.

21. Palla, Robert L., Jr., Water Usage Characteristics of Household Appliances and the Potential for Water Savings. Center for Consumer Product Technology, National Bureau of Standards, Washington, DC, December 1979.

22. R.S. Means Co., Inc., Building Construction Cost Data 1980, 38th annual edition. Kingston, MA, 1979.

23. Sharpe, William E., Water Conservation and Wasteflow Reduction in the Home, Special Circular No. 184. Pennsylvania State University, April 1974.

24. Sharpe, William E., "Water Conservation with Water Saving Devices," Water Conservation with Water Saving Devices, T. B. Shelton, ed. Proceedings of a Conference, Rutgers University, New Brunswick, NJ, November $30,1976$.

25. Stoner, Carol Hupping, ed., Goodbye to the Flush Toilet. Rodule Press, 1977.

26. U.S. Bureau of the Census, "1977 Annual Housing Survey," unpublished tabulation of the Department of Energy Supplement, Washington, DC. 
27. U.S. Bureau of the Census, Statistical Abstract of the United States: 1979, 100th edition. Washington, DC, 1979.

28. U.S. Department of Energy, Office of Conservation and Solar Energy, Federal Register, Vol. 45, No. 16 (October 27, 1980).

29. U.S. Environmental Protection Agency, Construction Costs for Municipal Wastewater Treatment Plants: 1973-1978, EPA/430/9-80-003. Washington, DC, April 1980 .

30. U.S. Environmental Protection Agency, Office of Water Program Operations, Determining Wastewater Treatment Costs for Your Community. Washington, DC, 1979 .

31. University of Illinois at Urbana-Champaign, "Water Conservation," Council Notes, Vol. 2, No. 3 (Winter 1977).

32. "Washing Machines," Consumer Reports, October 1975.

33. Washington Suburban Sanitary Commission, Citizens Advisory Committee, "How to Decrease the Demand for Water Through Changes to the Rate Structure," June 1977.

34. Washington Suburban Sanitary Commission, WSSC Pipeline. Hyattsville, MD, October 1978.

35. Winter, Fred and Galowin, Lawrence S., Criteria and Evaluation for TwoStep Flush Devices for Water Closets, National Bureau of Standards Interagency Report 81-2296. Washington, DC, June 1981. 
1. PUBLICATION OR REPORT NO.

NBSIR $81-2304$
2. Performing Organ. Report No.

3. Publication Date

August 1981

4. TITLE AND SUBTITLE

Economic Framework for Cost-Effective Residential Water Conservation Decisions

5. AUTHOR(S)

Stephen F. Weber, Bruce E. Thompson, and Barbara C. Lippiatt

6. PERFORMING ORGANIZATION (If joint or other than NBS, see instructions)

NATIONAL BUREAU OF STANDARDS

DEPARTMENT OF COMMERCE

WASHINGTON, D.C. 20234

9. SPONSORING ORGANIZATION NAME AND COMPLETE ADDRESS (Street, City, Srate, ZIP)

7. Contract/Grant No.

8. Type of Report \& Period Covered

Final

U.S. Department of Housing and Urban Development

Office of Policy Development and Research

4517 th Street, S.W.

Washington, D.C. 20410

10. SUPPLEMENTARY NOTES

[D Document describes a computer program; SF-185, FIPS Software Summary, is attached.

11. ABSTRACT (A 200-word or less factual summary of most significant information. If rocument includes a significant bibliography or literature survey. mention it here)

This report presents an economic framework for utilities to use in recommending water-saving devices that are cost-effective for homeowners. A variety of devices designed to save water used in water closets, showers, and indoor faucets are described in terms of their costs and benefits. The cost components considered are acquisition, installation, maintenance, and replacement costs. Benefits considered are water savings, avoidance of wastewater treatment, and energy savings in the case of reduced hot water use. A critical factor affecting the dollar value of benefits to homeowners is the price they pay for water. An analysis of water rate schedules, based on a national sample of 90 water utilities, indicates that homeowners' actual benefits from saving the last unit of water (as measured by its marginal price) are considerably lower than the average price paid for water. Thus, estimated water bill reductions will frequently be overstated if calculated on the basis of average price. The economic framework for selecting devices evaluates both mutually exclusive and compatible devices that are either modifications of existing plumbing fixtures or features of newly installed fixtures.

12. KEY WORDS (Six to twelve entries; alphabetical order; copitalize only proper names; and separate key words by semicolons) benefits; cost-effective; costs; economic analysis; economic decision framework; energy conservation; marginal price; net present value; residential water conservation; wastewater treatment; water rate schedules; water-saving devices. 13. AVAILABILITY

Ex Untimited

For Official Distribution. Do Not Release to NTIS

Order From Superintendent of Documents, U.S. Government Printing Office, Washington, D.C. 20402.

\begin{tabular}{|} 
14. NO. OF \\
PRINTED PAGES \\
64 \\
\hline 15. Price \\
\\
$\$ 8.00$
\end{tabular}

XX Order From National Technical Information Service (NTIS), Springfield, VA. 2216I 


; 